\title{
Exposure to Common Enemies can Increase Political Polarization: Evidence from a Cooperation Experiment with Automated Partisans
}

\author{
Eaman Jahani, ${ }^{1 \dagger}$ Natalie Gallagher, ${ }^{2 \dagger}$ Friedolin Merhout, ${ }^{3}{ }^{4 \dagger}$ Nicolo Cavalli, ${ }^{5}{ }^{6 \dagger}$ \\ Douglas Guilbeault, ${ }^{7 \dagger}$ Yan Leng, ${ }^{8 \dagger}$ Christopher A. Bail,,${ }^{9} 10 \dagger *$ \\ ${ }^{1}$ Institute for Data, Systems and Society, Massachusetts Institute of Technology, \\ 50 Ames St, Cambridge, MA 02142, USA \\ ${ }^{2}$ Department of Psychology, Northwestern University, \\ 2029 Sheridan Road, Evanston, IL 60208, USA \\ ${ }^{3}$ Department of Sociology, University of Copenhagen, \\ 1353 Copenhagen K, Denmark \\ ${ }^{4}$ Centre for Social Data Science, University of Copenhagen, \\ 1353 Copenhagen K, Denmark \\ ${ }^{5}$ Carlo F. Dondena Centre, Bocconi University, \\ 1 Via Guglielmo Röntgen, Milan, Italy 20136 \\ ${ }^{6}$ Nuffield College, Oxford University, \\ 1 New Road, Oxford, United Kingdom OX1 1NF \\ ${ }^{7}$ Haas School of Business, University of California, Berkeley, \\ 2220 Piedmont Ave, Berkeley, CA 94720, USA \\ ${ }^{8} \mathrm{McCombs}$ School of Business, The University of Texas at Austin, \\ 2110 Speedway, Austin, TX 78705 \\ ${ }^{9}$ Polarization Lab \& Sociology Department, Duke University, \\ Soc. Psych Hall, Durham, NC 27708 \\ ${ }^{10}$ Sanford School of Public Policy, Duke University, \\ Box 90239, Durham, NC 27708
}

*To whom correspondence should be addressed: christopher.bail@ duke.edu.

$\dagger$ These authors contributed equally to this work. 
ABSTRACT: Longstanding theory indicates the threat of a common enemy can mitigate conflict between members of rival groups. We tested this hypothesis in a pre-registered experiment where 1,670 Republicans and Democrats in the United States were asked to complete a collaborative online task with an automated agent or "bot" that was labelled as a member of the opposing party. Prior to this task, we exposed respondents to primes about a) a common enemy (involving threats from Iran, China, and Russia); b) a patriotic event; or c) a neutral, apolitical prime. Though we observed no significant differences in the behavior of Democrats as a result of these primes, we found that Republicans-and particularly those with very strong conservative views-were significantly less likely to cooperate with Democrats when primed about a common enemy. We also observed lower rates of cooperation among Republicans who participated in our study during the 2020 Iran crisis, which occurred in the middle of our fieldwork. These findings indicate common enemies may not reduce inter-group conflict in highly polarized societies, and contribute to a growing number of studies that find evidence of asymmetric political polarization. We conclude by discussing the implications of these findings for research in social psychology, political conflict, and the rapidly expanding field of computational social science.

Political polarization—or the tendency for members of rival political groups to adopt increasingly distant opinions about how to solve social problems-is pervasive in many Western Democracies today (1-5). In the United States, for example, 59.3\% of Democratic voters believe federal aid to the poor should be increased compared to only $20.2 \%$ of Republicans voters. Conversely, $68.9 \%$ of Republicans believe immigration to the United States should be decreased, compared to $21.9 \%$ of Democrats (6). Such discrepancies extend beyond policy is- 
sues into the attitudes of Republicans and Democrats towards each other. The proportion of Americans identified with a political party who would be uncomfortable if their child married someone of the opposite party increased from less than $10 \%$ in 1960 to $33 \%$ in 2012 (7). These trends continued after the divisive 2016 presidential election and the impeachment trial of President Donald Trump.

Though many explanations have been offered for growing political polarization, relatively little research has identified solutions to this urgent social problem (3). One possibility is that members of rival groups will set aside their differences if they face a shared threat from a common enemy (8-10). This theory - which has roots in social psychology, social network analysis, and philosophy that date back to a Sanskrit treatise on warfare from the 4th century B.C.- - has been invoked to explain the consolidation of rival factions and even the emergence of the modern nation-state $(11,12)$. The concept has also been formalized as part of social balance theory, which examines how inter-group solidarities and animosities result from a complex equilibrium of agreements and compromises between friends and foes; or, to cite the popular triadic formalization of this concept: "the enemy of my enemy is my friend" (8).

Different proposals have been offered to explain this phenomenon. Within the common ingroup identity model, this effect occurs because members of rival factions come to realize they have more in common with each other than their shared enemy (13). In the United States, for example, some argue that the threat of the Soviet Union prevented political polarization throughout the Cold War because it primed a sense of shared fate that inspired Americans to set aside their differences to confront a formidable enemy (14-16). Yet it is also possible that simply priming national identity might have a similar effect, if the mechanism of depolarization is reminding rival factions about their similarities to each other (17). Another possibility is that the common enemy effect is driven by fear of out-groups, or some combination of this process and in-group favoritism (17-19). 
At the same time, the degree to which a common ingroup identity is achievable - and the expected cooperation - depends upon the nature of the existing rivalry, and on how those rivals understand their relationship to the common outgroup. When rival groups are sufficiently antagonistic — as may be true of Democrats and Republicans today— the common ingroup identity may actually feel like a threat to the existing partisan identity, leading to a decrease in cooperation (11). This means that an external threat increasing reliance on one's relevant identity could lead partisans either to feel more American, or to become more closely tied to their own partisan group (20). To rephrase this hypothesis in the language of social balance theory: people will only consider the enemy of their enemy to be a friend if they can see one of the enemies as a potential ally.

Studying whether common enemies reduce political polarization presents numerous methodological challenges. To begin, external threats are not randomly distributed across countries or historical contexts. Therefore, rigorous causal inference is thus not possible with observational data. Similarly, field experiments that expose members of rival groups to common enemies would either be unethical, logistically impossible, or both. Simple survey experiments, however, lack the external validity necessary to demonstrate whether exposure to a common enemy shapes meaningful intergroup behavior. In this study we developed a hybrid approach that captures behavioral outcomes. We recruited a large group of Democrats and Republicans to participate in a collaborative task on an online platform. By exposing the respondents to different types of primes, we study whether partisans collaborate with each other when additional financial incentives are at stake.

Figure 1 describes our research design. From October 2019 to January 2020, we recruited 1,670 self-identified Republicans and Democrats who live in the United States from an online panel to participate in our study via an online platform we created. Participants were randomized into one of three priming conditions. In the first condition, respondents were asked to 
read a neutral, apolitical article about early human drawings that were recently discovered by archaeologists in South Africa. This condition served as the control for the two other primes. In the second condition, we studied the effect of priming in-group identity alone by asking respondents to read an article about the Fourth of July celebrations in several U.S. cities. In the third condition, we exposed respondents to a common enemy prime using an article describing how Russia, Iran, and China were closing ranks against the United States after a military incident. As our Supplementary Materials describe, these articles were carefully selected from a group of 43 candidate primes from Reuters.com that we pretested in order to ensure they created the expected priming effect among both Republicans and Democrats. We elected to use articles from Reuters.com because previous studies indicate it is equally trusted by Republicans and Democrats as an objective news source (21).

To collect a behavioral measure of political polarization, we told each respondent they could receive additional pay for providing accurate estimates to a question. This question was as follows: "What percentage of immigrants between 2011 and 2015 were college educated?" Respondents first estimated the answer to this question themselves, with no further input. After making their own estimate, they were exposed to the guess of an automated agent or "bot" which impersonated a member of the opposing political party who was also involved in the estimation task. The bot always provided an initial estimate that was 50 percentage points plus a small amount of random noise away from the participant's initial guess. After viewing this response, participants were invited to revise their estimates. Below, we report how much participants revised their predictions after being exposed to an estimate they believed was from a member of the opposing political party. The extent to which each respondent updated their estimate towards that of the bot describes the degree to which participants are willing to cooperate with a member of the opposing party when incentivized for accuracy. Since accuracy incentives can reduce partisan bias in estimations (22), this serves both to motivate participants to be accurate 


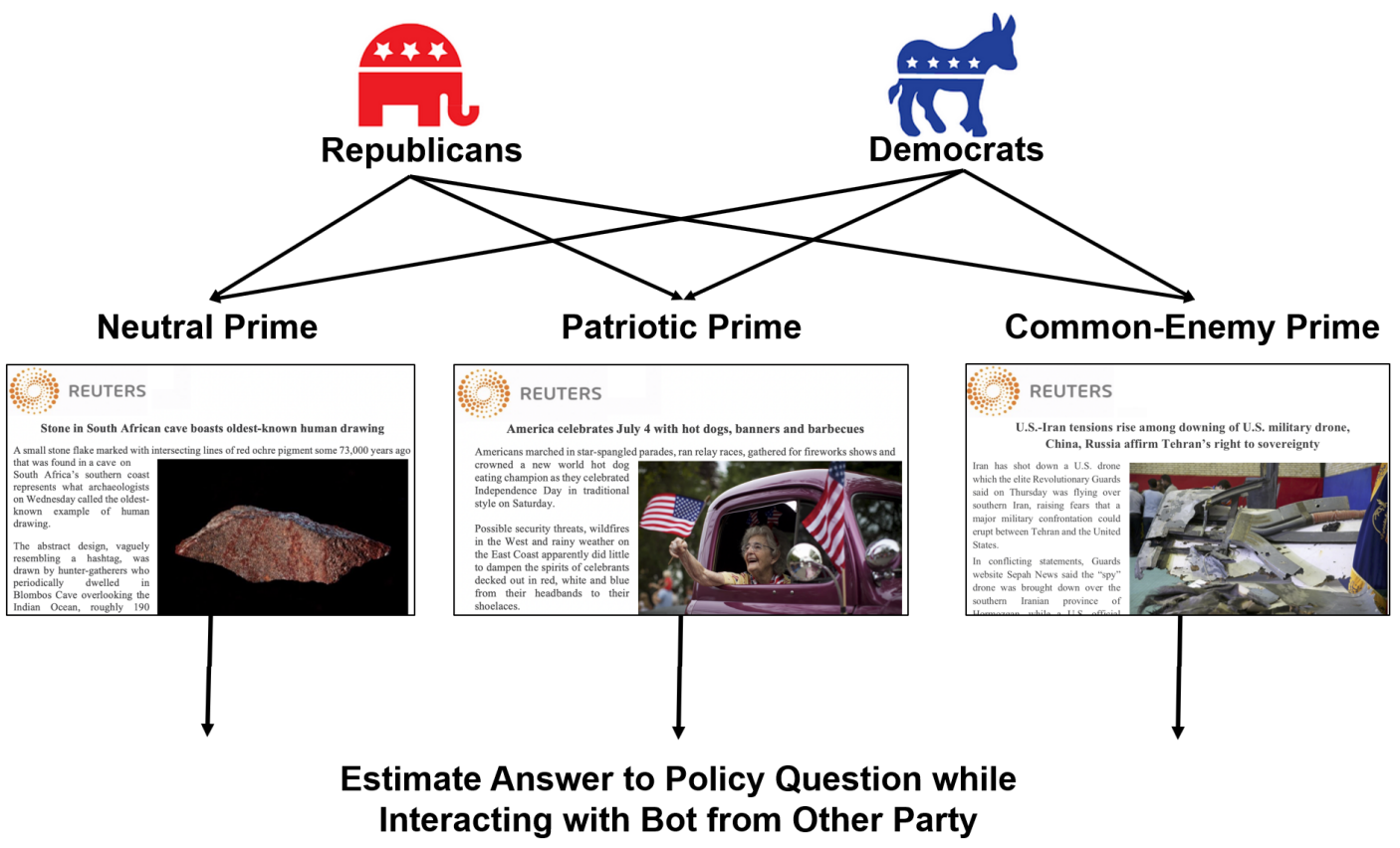

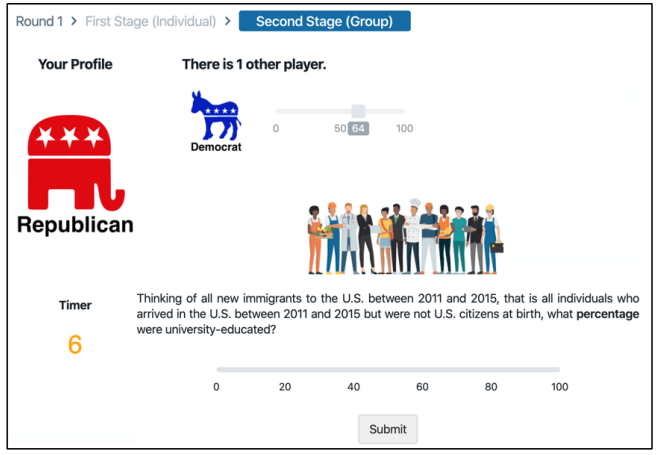

(The Interface for Republican Participants)

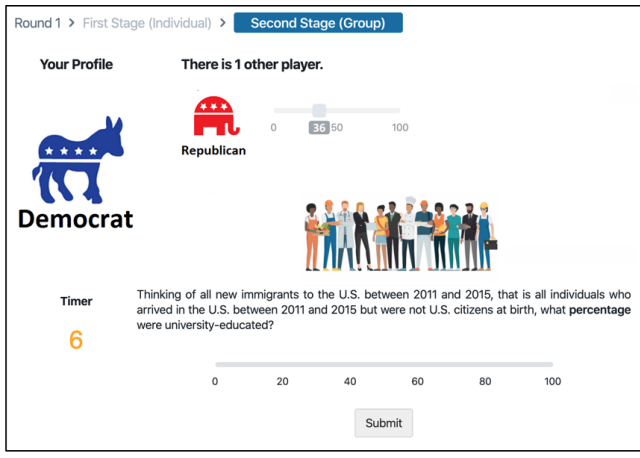

(The Interface for Democratic Participants)

Figure 1: Schematic illustrating the experimental design. 1,670 Republicans and Democrats were randomized into one of three experimental conditions: (1) the neutral prime condition, where they read an article about early human carvings in South Africa; (2) a patriotic prime condition, where they read an article about July 4th celebrations; and (3) a common-enemy prime condition, where they read an article about the combined threat of Iran, China, and Russia. After reading the article, each participant was offered financial incentives to estimate the answer to a question about a political issue and told that their compensation would increase according to the accuracy of their response. After submitting their first estimate, participants were shown the estimate of an automated agent or "bot" impersonating a member of the opposing party. By measuring how much members of each party revise their answers towards the bot in the subsequent round of estimation, we measure how much members of each party collaborate with the opposing party within each treatment condition. 
and reduce bias across our conditions.

We estimate the effect of exposure to a common enemy and patriotic prime, respectively, by comparing whether people in these two conditions updated more or less towards the bot impersonating the opposing party than those in the neutral, control condition. As Figure 2 shows, we observed no significant differences in the willingness of Democrats to update their estimates towards the Republican bot across each priming condition $(\mathrm{p}>0.05, \mathrm{~N}=530)$. In contrast, Republican participants were significantly less likely to cooperate with the bot they believed to be a Democrat after exposure to the common enemy prime than Republicans in the control condition ( $\mathrm{p}<0.01, \mathrm{~N}=314$ ). What is more, the strength of partisanship among Republicans explained this effect. As Figure 3 shows, Republican respondents who were in the top 10th percentile of a thermometer-based measure of in-group favoritism were less likely to update towards the bot impersonating a Democrat than those with less strong partisan views ( $\mathrm{p}$ $<0.001, \mathrm{~N}=484$ ). We observed no significant differences among Democrats using the same strength of partisanship measure.

We further validated these findings via a natural experiment that occurred during our fieldwork (14). On January 3rd, 2020, United States special forces in Iraq assassinated Qasem Suleimani, an influential Iranian general. This triggered a major geopolitical crisis that many people believed would cause the outbreak of war between the two countries. The event occurred in the middle of our fieldwork, which began in October 2019 and concluded in late January 2020. Since our common enemy prime involved discussion of US-Iran relations, this unanticipated exogenous event presented us with another experiment, orthogonal to our priming treatments, to test how increasing the salience of a common enemy interacts with extant partisan tensions. As Figure 4 shows, we found Republicans were less likely to cooperate with Democrats after the assassination than before this event, regardless of which priming condition they received $(\mathrm{p}<.01, \mathrm{~N}=485)$. This finding suggests that Republicans are less cooperative 


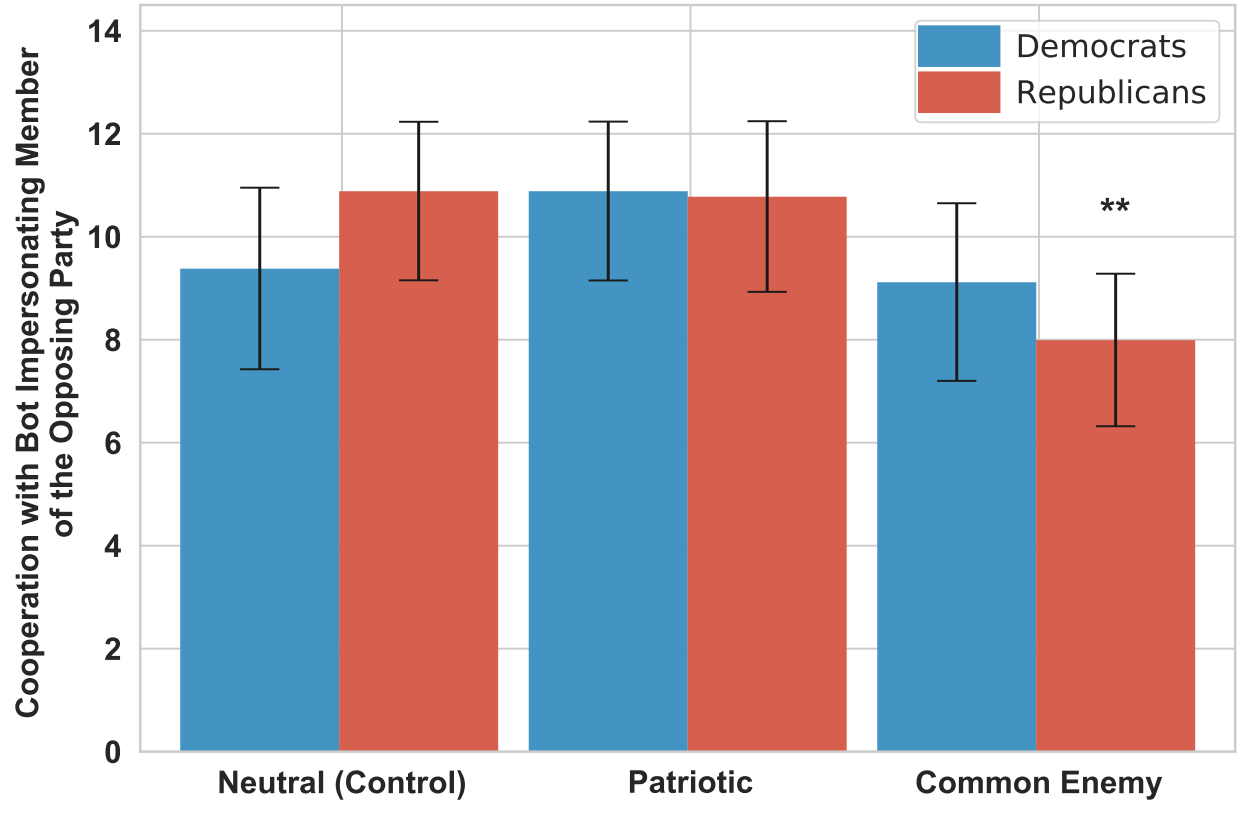

Figure 2: Amount of cooperation among study participants with a bot impersonating member of the opposing party during collaborative online task across experimental conditions by political party. Vertical axis describes the post-stratified average belief update (in percentage points) for participants in each priming condition, where strata are defined by gender, political knowledge, the accuracy of initial guess, and awareness of bot's membership in the opposing party. Larger values indicate more cooperation or larger updates toward the bot's estimates. The neutral condition provides a baseline of comparison or a "control" condition. Error bars display 95\% confidence intervals. $* * \mathrm{p}<0.01$. 


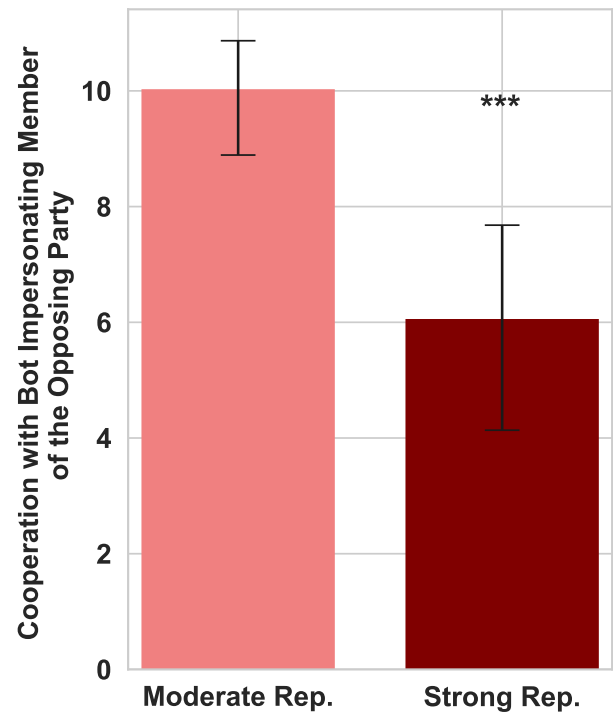

Figure 3: Amount of cooperation among Republican study participants across all prime conditions with a bot impersonating a Democrat during collaborative online task by strength of partisanship. Vertical axis describes the post-stratified average belief update (in percentage points), where strata are defined by gender, political knowledge, the accuracy of initial guess, and awareness of bot's membership in the opposing party. Larger values indicate more cooperation or larger updates toward the bot's estimates. Strong republicans are defined as those who are in the top 10th percentile of partisan identification measured by feeling thermometers. Moderate Republicans are those in all other percentiles. These "moderate republicans" provide a baseline of comparison. Error bars display 95\% confidence intervals. *** $\mathrm{p}<0.001$. 




Figure 4: Amount of cooperation among Republican study participants across all prime conditions with a bot impersonating a Democrat during collaborative online task before and after the 2020 Iran crisis. Vertical axis describes the post-stratified average belief update (in percentage points), where strata are defined by gender, political knowledge, the accuracy of initial guess, and awareness of bot's membership in the opposing party. Larger values indicate more cooperation or larger updates toward the bot's estimates. The "Before Iran Crisis" outcomes provide a baseline of comparison. Error bars display $95 \%$ confidence intervals. $* * p<0.01$.

with Democrats when they are exposed to a sudden external threat.

To the best of our knowledge, this study provides the first experimental analysis of the behavioral effects of exposure to a common enemy in the United States during a period of extreme political polarization. Contrary to widespread belief, we found that threats from a common enemy either lead to no changes in cooperative behavior among partisans or- in the case of Republicans - lead them to cooperate even less with Democrats. These findings are consistent with a growing number of studies that document asymmetric polarization- or patterns of intergroup animosity that appear to be driven more by Republicans than Democrats (23-26). These results suggest that political narratives about global, combative conflicts-which politicians often invoke to rally patriotic support-may have the unintended consequence of increasing polarization within a nation. 
Our study provides several important contributions to the study of political polarization and computational social science more broadly (27). First, we contribute to a growing body of work on "backfire effects" in political psychology, where exposure to the attitudes and beliefs of a rival political group have been shown to exacerbate partisan bias. A number of recent studies have found asymmetric backfire effects where partisan bias is particularly amplified among Republicans as a result of cross-party interaction. For example, one recent study of cross-party social media exposure found that Republicans were more likely to increase their partisan bias in response to exposure to social media messages from opinion leaders from the opposing party (24). This result is consistent with social learning experiments which show that partisan priming can lead Republicans to be significantly less cooperative than Democrats when discussing climate change (25). Since cross-party interaction appears to further entrench partisan bias, many have recently proposed that exposure to a common enemy may be one of the few ways to decrease political tensions $(21,28,29)$. However, the results from our study indicate exposure to a common enemy may not be sufficient to eliminate partisan boundaries to cooperation, and may even amplify political tensions — particularly among Republicans.

Our finding does not fit the traditional expectation from balance theory - that exposure to a common outgroup should increase superordinate group identification and cooperation. Yet this theory still offers insight about our results. In societies that experience extreme polarizationsuch as the United States today-tensions between Republicans and Democrats may be high enough that political rivals are perceived as more closely connected to the external enemy than the nation itself $(9,11,18,28)$. Under such conditions, the threat of a common enemy may increase political tensions among rival groups. Together, these findings provide unprecedented insight into the behavioral dynamics of political polarization in highly polarized societies such as the United States. 


\section{Supplementary Materials}

\subsection{Recruitment of Study Participants}

We conducted the recruitment for this study using a panel of 3,177 self-identified Democrats and Republicans collected via CloudResearch during spring 2019. Cloud Research (formerly known as TurkPrime) is an online survey company that enables the collection of high-quality survey panels from Amazon Mechanical Turk users using advanced screeners to remove low-quality respondents and inauthentic survey respondents. Though this source does not provide samples that are representative of the United States population, recent research has demonstrated that samples drawn from CloudResearch capture more variation among important demographic and political belief covariates than in-person lab samples $(30,31)$. During the profiling process, each respondent was asked a series of questions about their demographic characteristics and political beliefs. Between October 2019 and January 2020, we invited 3,162 participants from the online panel to participate in the study. The invitations and study description specified that participants would receive an initial $\$ 2$ for participating in a five minute online task where with other people with an additional bonus of up to $\$ 1$ based upon their success in the online task. Since we expected performance in the estimation task to depend on the feedback participants received from the bots - and since bot feedback in the first round was based on initial participant input (participant input $+/$ - 50 percentage points)—we ultimately compensated all respondents with the full bonus amount regardless of the accuracy of their answers.

1,692 out of the 3,162 people invited to join the study initially agreed to participate for a raw response rate of 53.5\%. As Table 1 shows, we observed no significant differences in response rates between Republicans and Democrats. We ran additional models (not shown) that examined whether age, gender, race and ethnicity, level of education, or income level were significant predictors of non-response. Of these, only age was a significant predictor of non-response: 
Table 1: Study Response Rates by Party

\begin{tabular}{llll}
\hline \hline & Did not Participate in Study & Participated in Study & Raw Response Rate \\
\hline Democrats & 569 & 655 & 53.5 \\
Democrat Leaners & 205 & 219 & 51.7 \\
Republicans & 549 & 651 & 54.3 \\
Republican Leaners & 147 & 167 & 53.2 \\
\hline \hline
\end{tabular}

older people were slightly more likely to participate $(\mathrm{p}<.001)$. Our sample also compares favorably to the national population on each of these measures. The mean age of respondents in our sample is 42.20 compared to the national average of 37.84 reported by the 2016 American Community Survey. Our respondents were 52.2\% female, compared to the national average of $51 \%$. However, our sample contained fewer racial minorities than the national average. $82.2 \%$ of respondents were white or Caucasian compared to $70 \%$ (the national average).

\subsection{Experimental Procedure}

Before participants were forwarded to the online platform where they performed the collaborative task, we directed them to an interface that asked them to provide their MTurk "worker id" (a unique identifier given to each MTurk worker by Amazon). Participants were then redirected to the study platform that was developed using Empirica, an open-source "virtual lab" framework for multiplayer interactive experiments (32). Before proceeding to the experiment on the platform, participants first read an informed consent dialogue detailing the study process, the conditions for compensation, and their rights as study participants. If they consented to participate in the study, respondents advanced to a screen showing a profile that was pre-populated with the age, gender, and party identification they listed for themselves when they first joined the panel used to recruit respondents to the study. Participants were offered the opportunity to change these details before proceeding to the next screen on the platform 5. Throughout the 


\section{Profile Check}

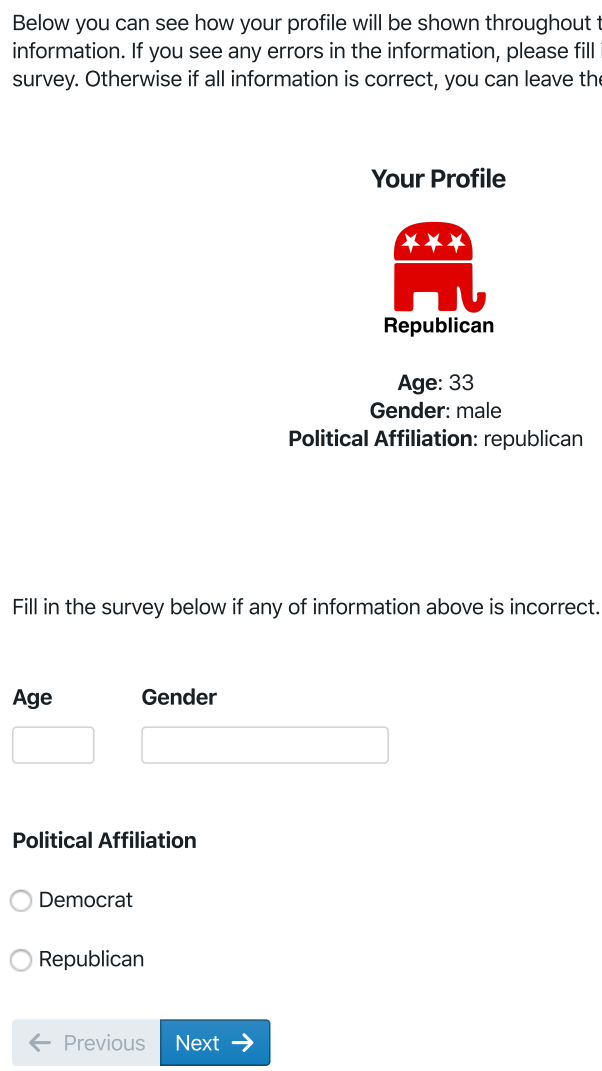

Figure 5: Participants could check and update their profile upon entering the platform.

game, each participant saw the symbol of their political party as their profile.

Before entering the priming conditions, participants were instructed to complete an example of the estimation task to ensure they understood the instructions. During this example task, they were shown the experimental estimation interface, but with a different political question than that which was used in the main study: "What percentage of food stamp (SNAP) recipients do you believe are employed full-time or part-time?". The example task instructions were divided into two pages. The first page introduced the first stage of the task in which participants had to enter their initial estimate without receiving any input from other players (individual stage). 


\section{An Example Game}

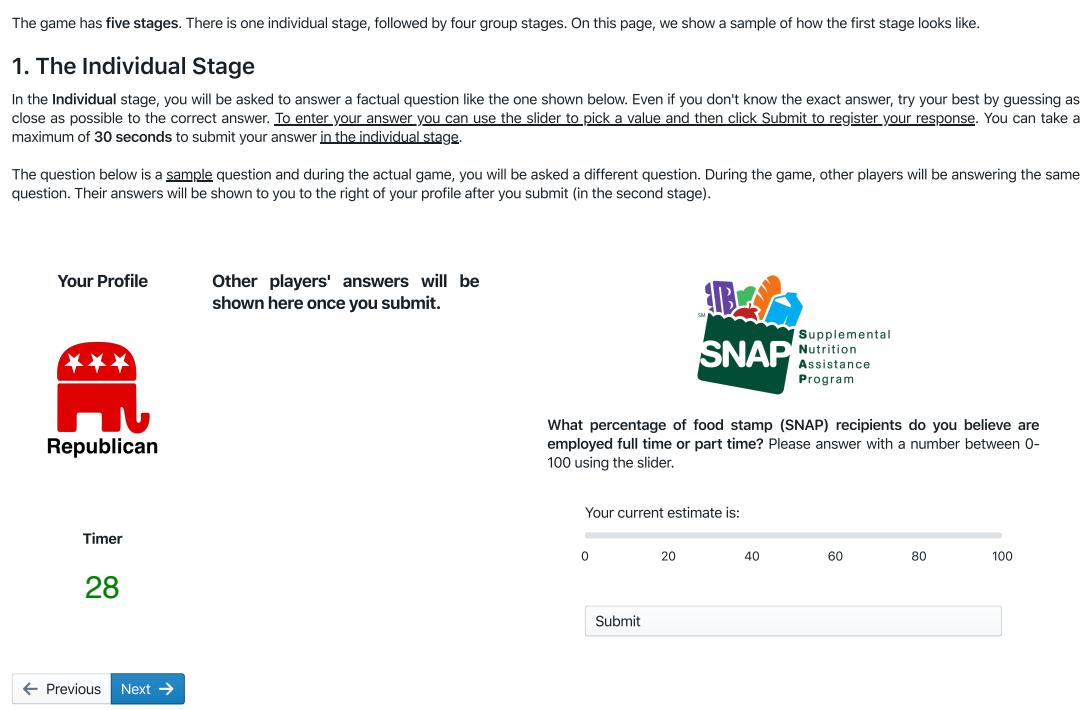

(a)

\section{An Example Game}

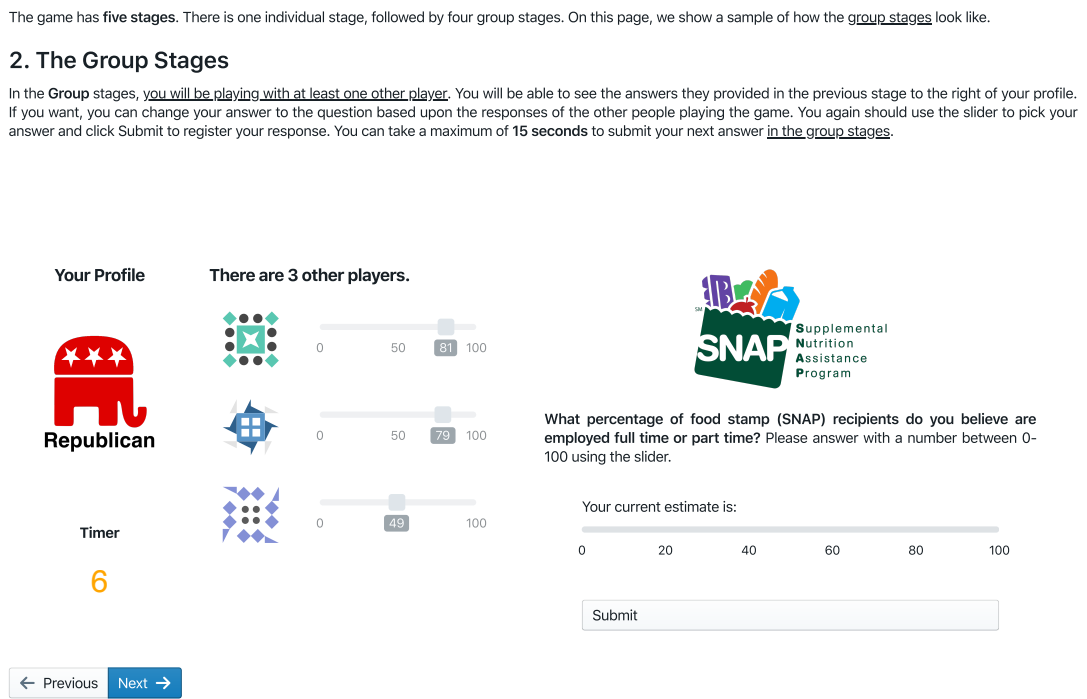

(b)

Figure 6: (a) Participants were first shown an example with instructions for the first stage of the game in which they provided their individual estimates independently. (b) Participants were then shown an example with instructions for the subsequent stages of the game in which they could update their estimates based on the estimate of other players (i.e. a bot). 
This stage is illustrated in Figure 6a. The second instruction page explained that subsequent rounds, users are provided with other players' estimates and are given the opportunity to update their previous estimate, as shown in Figure 6b. The other players' profiles did not include any political party symbols during this trial game. The instructions mentioned that the game has a total of five rounds, with the first round recording the individual estimate of participants. The subsequent four rounds allowed respondents to update their estimates based those of other players from the previous round. After completing the example estimation task, participants were informed the would receive $\$ 2$ for completing the online task and offered up to an additional $\$ 1$ based upon the accuracy of their estimates to the question asked. However, as we previously stated, all participants received the full bonus regardless of their accuracy.

After completing the on-boarding and training process, participants were randomized into one of three priming conditions (neutral, patriotic, or common-enemy). We provide an extensive description of how we chose these primes in the following section of our Supplementary Materials. In each condition, participants read the following prompt: "Please read the following article taken from Reuters, a non-partisan news outlet. On the next screen, we are going to ask you several questions about the article. You will need to answer these correctly to advance to the game." Next, we asked respondents to answer three questions about facts presented in the article. Respondents were allowed to re-read the article if they failed to answer the questions correctly, and allowed to re-take this test multiple times. These questions achieved two goals. First they helped us identify participants who were not paying attention or actively engaged in the online ask - a common problem with respondents recruited from online panels where they cannot be observed in person. Second, by allowing the participants to go back and forth between the article and the questions, we ensured that participants eventually read the article, since the questions were open-ended and respondents could not simply continually try different response categories in order to advance. The questions were also designed to further reinforce 


\section{REUTERS}

\section{Stone in South African cave boasts oldest-known human drawing}

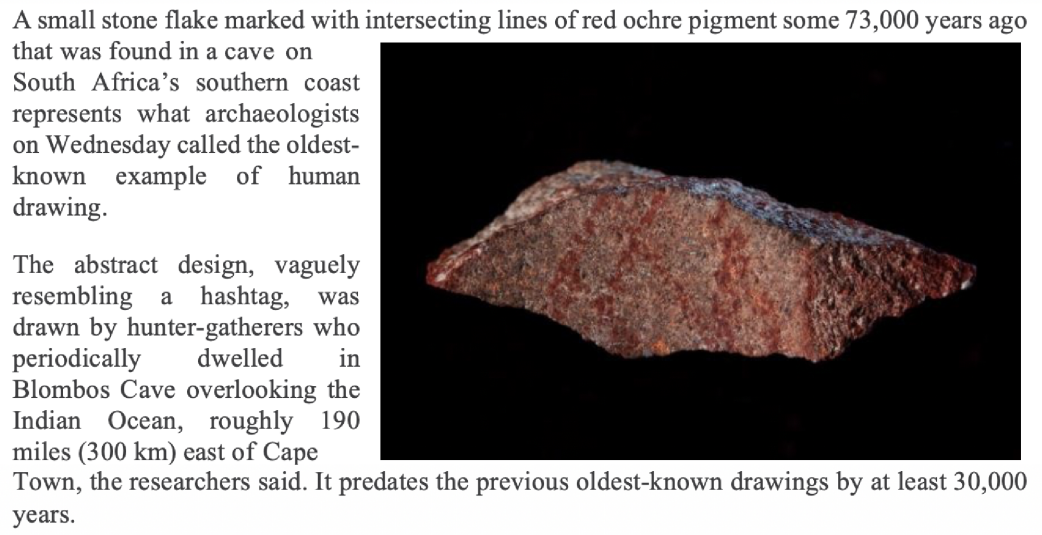

years.

While the design appears rudimentary, the fact that it was sketched so long ago is significant, suggesting the existence of modern cognitive abilities in our species, Homo sapiens, during a time known as the Middle Stone Age, the researchers said.

The cross-hatched design drawn with ochre, a pigment used by our species dating back at least 285,000 years ago, consists of a set of six straight lines crossed by three slightly curved lines. The coarse-grained stone flake measures about $1-1 / 2$ inches $(38.6 \mathrm{~mm})$ long and $1 / 2$-inch $(12.8$ $\mathrm{mm}$ ) wide.

"The abrupt termination of all lines on the fragment edges indicates that the pattern originally extended over a larger surface. The pattern was probably more complex and structured in its entirety than in this truncated form," said archaeologist Christopher Henshilwood of the University of Bergen in Norway and the University of the Witwatersrand in South Africa, who led the research published in the journal Nature.

"We would be hesitant to call it art. It is definitely an abstract design and it almost certainly had some meaning to the maker and probably formed a part of the common symbolic system understood by other people in this group," Henshilwood added.

Other Blombos Cave artifacts of similar age included ochre pieces engraved with abstract patterns resembling the one drawn on the stone as well as ochre-covered shell beads. Blombos Cave artifacts dating from 100,000 years ago included a red ochre-based paint.

"All these findings demonstrate that early Homo sapiens in the southern Cape used different techniques to produce similar signs on different media," Henshilwood said. "This observation supports the hypothesis that these signs were symbolic in nature and represented an inherent aspect of the advanced cognitive abilities these early African Homo sapiens, the ancestors of all of us today."

Homo sapiens first appeared more than 315,000 years ago in Africa, later trekking to other parts of the world.

\section{Figure 7: The article used in the control condition.}




\section{REUTERS}

America celebrates July 4 with hot dogs, banners and barbecues

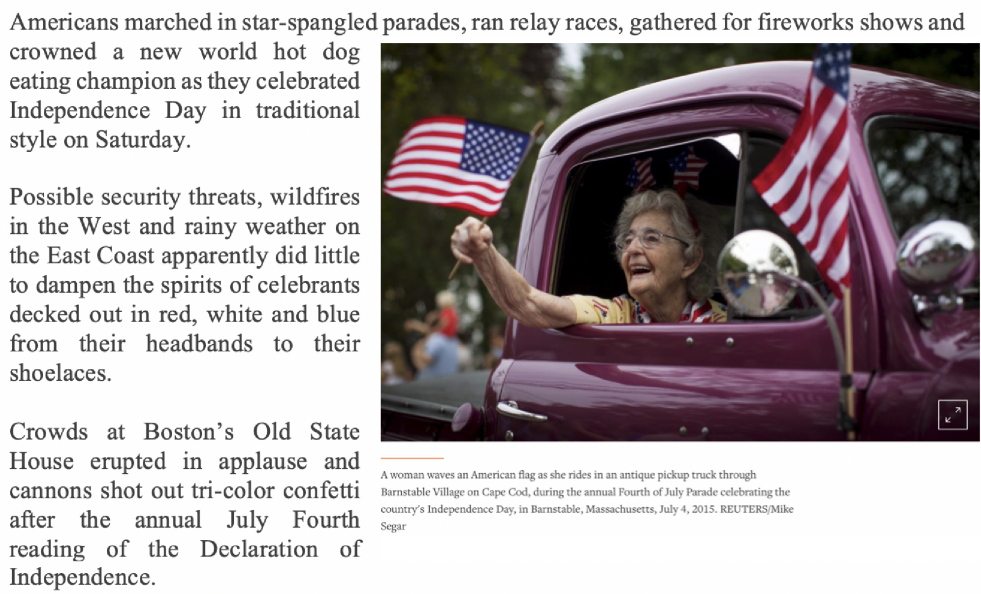

Meskie Hyman, 11, exuded patriot pride in a star-spangled shirt and a hairband with two American flags that fluttered under cloudy skies in Maplewood, New Jersey.

"I love that it's a free country and we have the right to speak. It lets us see everyone's potential and find our heroes," she said.

The crowd in Washington, D.C. watched a parade of brass bands, law enforcement motorcycle units, high school drum majorettes, antique cars and police and military detachments.

The National Mall, an open area west of the Capitol and site of a fireworks display expected to draw hundreds of thousands, was soggy from steady rain that had stopped by the time the parade started. Among them was Kearston Andrews, 26, who had travelled with her family from near Gainesville, Florida, and said security concerns had not affected them.

Even after promising an increased presence at weekend events, Massachusetts State Police maintained a holiday spirit, tweeting with a colloquial Boston phrase early Saturday "Have a wicked safe 4th of July!"

In a stunning upset on Coney Island, 23-year-old newcomer Matt Stonie grabbed the famed mustard-colored champion's belt after gobbling 62 hot dogs in 10 minutes in the annual Nathan's International Hot Dog Eating Contest.

Stonie, of San Jose, California, ousted long-time champion Joey "Jaws" Chestnut, who still holds a world record of 69 franks eaten in 2013. Miki Sudo hung onto the women's title, downing 38 hotdogs in 10 minutes.

A celebration in Austin, Texas featured country music legend Willie Nelson at an all-day picnic replete with music and drinking. And in Oklahoma, the record to beat at the "Watermelon Seed Spittin' World Championship" in Pauls Valley, about 60 miles $(100 \mathrm{~km})$ southeast of Oklahoma City, was 66 feet, 11 inches (20.41 meters), set in 1989 by Jack Dietz of Chicago, organizers said.

Figure 8: The article used in the patriotic priming condition. 


\section{REUTERS}

\section{U.S.-Iran tensions rise among downing of U.S. military drone, China, Russia affirm Tehran's right to sovereignty}

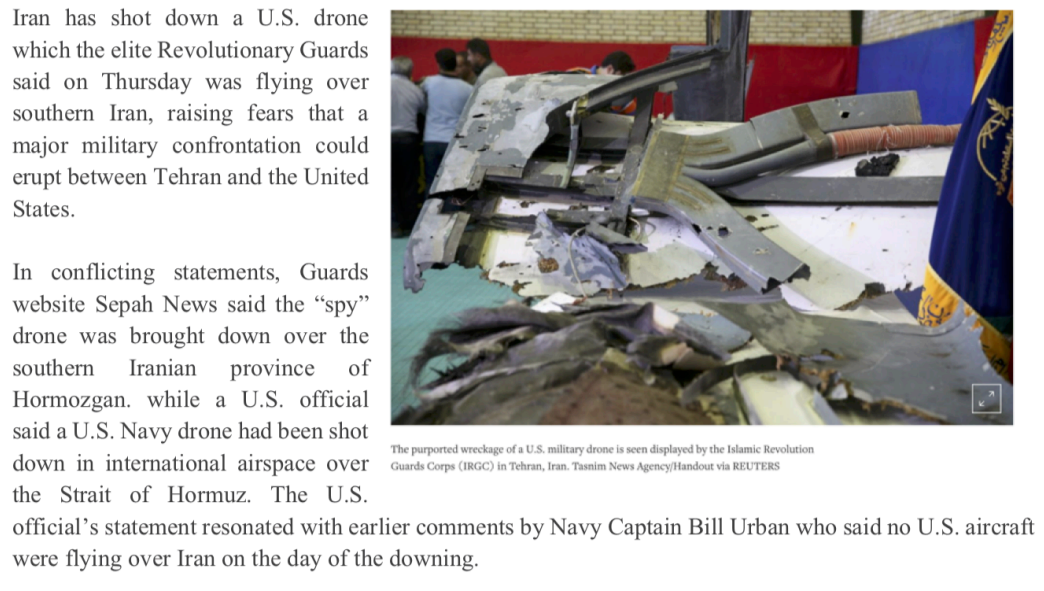

In response to the U.S.'s assertion, Russian Security Council Secretary Nikolai Patrushev stated that Russia had military intelligence showing the U.S. drone in Iranian airspace when it was shot down. This intelligence, Patrushev said, proved Iran was justified in shooting down the drone to protect its sovereignty over Iranian airspace.

Reaffirming Iran's resolve, a senior Iranian security official declared that, "our airspace is our red line and Iran has always responded and will continue to respond strongly to any country that violates it."

Tensions between the two countries have spiked since last year, when the United States reimposed sanctions on Iran after withdrawing from a 2015 nuclear deal between Iran and major world powers.

Among these escalating tensions, China offered strong support to Iran on Friday, with its top diplomat telling Iran's foreign minister that China opposes unilateral U.S. sanctions and acknowledges Tehran's rights to safeguard its interests.

Meeting in Beijing, Chinese State Councillor Wang Yi told Iranian Foreign Minister Mohammad Javad Zarif that given the important and rapidly-evolving situation, the two needed to strengthen communication and coordination.

"China resolutely opposes the U.S. implementation of unilateral sanctions, understands the current situation and concerns of the Iranian side, and affirms Iran's right to safeguard its legitimate interests," China's Foreign Ministry paraphrased Wang as saying.

Tensions might escalate further if the remaining parties to the nuclear deal cannot deliver the promised economic relief. In this case, Iran said it would start enriching uranium at higher levels than agreed to under the terms of the deal.

Figure 9: The article used in the common enemy priming condition. 


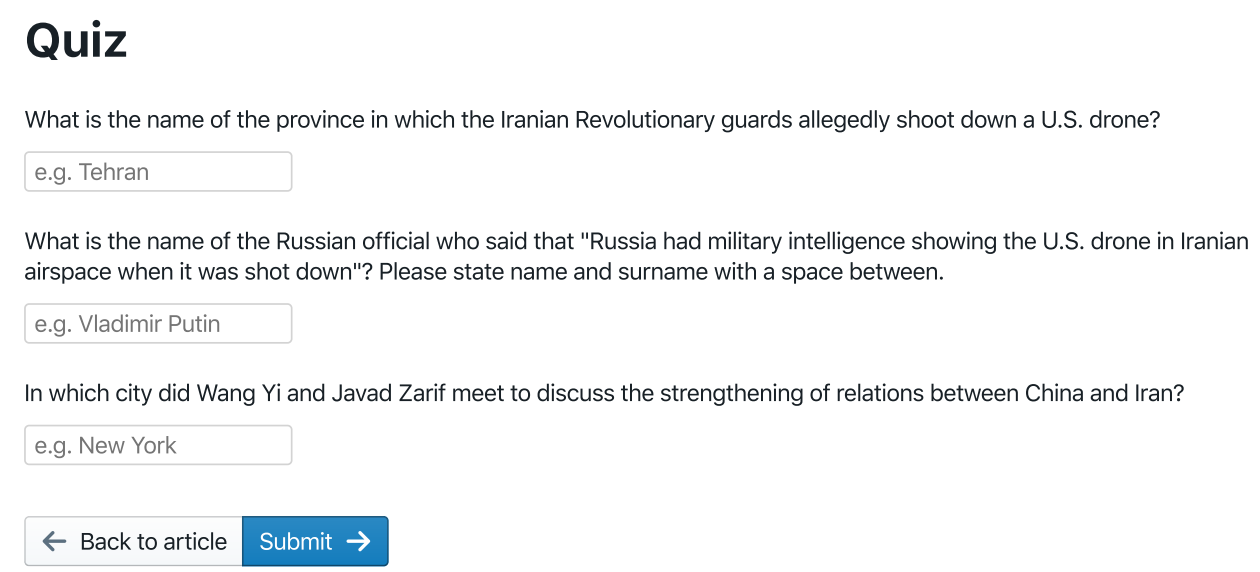

Figure 10: The quiz screen designed to ensure respondents absorbed key facts from the article (note: control and patriotic priming condition quizes not shown).

the effect of patriotic and enemy primes, for example by explicitly mentioning details of a military skirmish between the U.S. and Iran. The articles used as primes are shown in Figures 7, 8, 9. A sample of questions used to ensure respondents read key facts in the article is also shown in Figure 10.

Once each question was answered correctly, participants advanced to the estimation task, where they were asked to provide an estimate to the following question described in the main text: "Thinking of all new immigrants to the U.S. between 2011 and 2015-that is, all individuals who arrived in the U.S. between 2011 and 2015, but were not U.S. citizens at birth-what percentage were university-educated?" In the first round, participants provided an independent estimate, without exposure to the estimate from the bot impersonating a member of the opposing party. They had 30 seconds to read the question and provide an initial estimate.

In the subsequent four rounds, participants were given an opportunity to revise their estimate after being presented with the estimate of the other player-a bot described as a member of the opposing party_-from the previous round. In each round (from round 2 to round 5), participants had 15 seconds to react to the bot's estimate and update their previous estimate. This bot was 

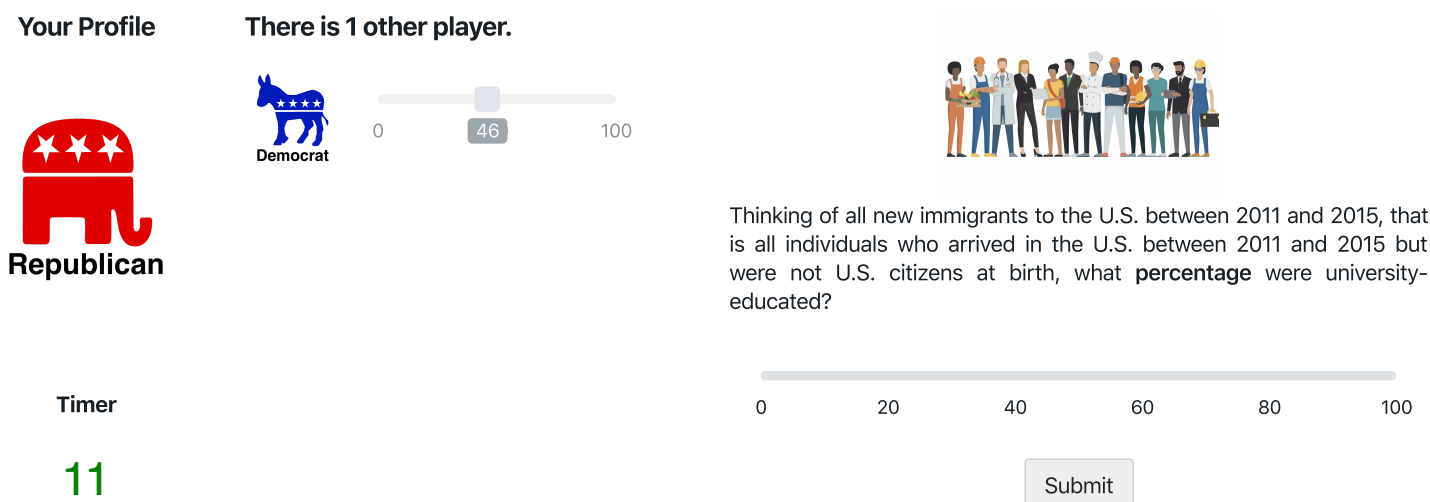

Thinking of all new immigrants to the U.S. between 2011 and 2015, that is all individuals who arrived in the U.S. between 2011 and 2015 but were not U.S. citizens at birth, what percentage were university-

Timer

Figure 11: The third round of a game in which a Republican participant is matched with a bot impersonating a Democrat. The slider to the right of the Democrat icon indicates the bot's estimate from the previous round.

programmed to initially provide an estimate that was 50 percentage-points plus a random integer (between -4 and 4) away from the participant's initial estimate. This manipulation allowed us to test the effect of each priming condition on the willingness of participants to revise their independent estimates toward the bot's estimate, regardless of their initial estimate. For each bot estimate displayed after round two, the bot either stuck to its initial guess (the stubborn bot) or moved its guess closer to the participant's guess. This "friendly bot" updated in a memoryless Bayesian fashion, such that the bot's estimate in round $t+1$ is:

$$
x_{\mathrm{b}, \mathrm{t}+1}=\frac{3}{4} x_{\mathrm{b}, \mathrm{t}}+\frac{1}{4} x_{\mathrm{p}, \mathrm{t}}+\text { uniform }(-3,3)
$$

where $x_{\mathrm{b}, \mathrm{t}}$ and $x_{\mathrm{p}, \mathrm{t}}$ are the bot's and the participant's estimates in round $t$ respectively, and uniform $(-3,3)$ corresponds to an integer drawn uniformly at random between -3 and 3 . Participants were randomly assigned to interact with the stubborn or friendly throughout the entire study. The participant's first update, which is the basis of our main results, is not affected by 
this variation in bot's behavior. By design, the behavior of the bots impersonating members of the opposing party could only affect participant's update pattern in the third, fourth and fifth rounds.

Figure 11 illustrates the third round of the estimation task. In all rounds (from round 2 to round 5), the other player's profile was shown next to the participant's profile. While the profile of the human participant included the icon of their political party (red elephants for Republicans and blue donkeys for Democrats), the bot's profile included the icon of the opposite political party. This layout was chosen in order to highlight the contrast in political identification between the participant and the bot.

After completing five rounds of the game, participants completed an exit survey. First, participants were asked a political knowledge question: "Which party has a majority of seats in the Senate?" Next, they were asked to identify the political party of the other player in the game as a manipulation check. They then estimated the political knowledge of the other player (i.e. the bot) in the game. Participants subsequently indicated their level of identification with five different groups using a single-item measure of identification: 1) Americans, 2) people in their state, 3) people in their neighborhood, 4) Democrats, and 5) Republicans. Finally, they completed a measure of their mood (the PANAS21) (33), and feeling thermometers towards a) in-groups (voters from their political party, and all Americans), b) out-groups (voters from the opposing political party, Russians, Iranians, and Chinese), and c) two distractor groups (Texans and Californians). After the exit survey, participants were provided with information about how to request compensation for their time. They also had the opportunity to respond to several questions about their experience on the platform. In particular, participants were asked to indicate whether they had previous familiarity with the estimation task and whether they attempted to look up the answer online. On the final page, participants were debriefed to inform them that they had actually performed the estimation task with a bot, and not a member of the 
opposing political party. A video that illustrates the entire participant experience is available here.

\subsection{Selection of News Articles for Treatment Conditions}

In order to identify neutral, patriotic, and common-enemy primes, we conducted multiple rounds of pre-testing of news articles to ensure that they created a) no response; b) a prideful response; or c) a fearful or threat response, respectively. Our pre-testing effort was further designed to ensure that neither Democrats nor Republicans were significantly more likely to respond to one of these primes. We chose to select articles from Reuters because previous studies indicate it as the most centrist news organization at the time of this writing (21). In the first round, we gathered and pre-tested a total of 42 articles from Reuters (12 neutral articles, 12 articles that prime patriotism, and 18 that describe a common enemy) from news coverage over the previous year. To ensure comparable length — and to expunge explicit partisan cues from the text of the prime-we edited the original Reuters articles before pre-testing them to an average length of 400 words. Each article was associated with a single image, sourced from the original publication.

Between March 29th and April 1st, 2019 we pretested the 42 articles by asking 566 respondents (347 Democrat and 219 Republicans) recruited from MTurk, to complete a survey on Qualtrics about their attitudes and feelings. This survey presented respondents with one article, randomly selected out of the set of 42 total articles, and asked the same set of questions used in the exit survey of the main study. We used an iterative process to select the three final articles. First, we searched for the article in each category (neutral, patriotic, or common enemy) that created equal shifts in party identification, identification with America, and emotional responses among both Republicans and Democrats. To ensure that respondents viewed the potential primes as realistic news stories, our pre-testing survey also included open-ended 
Table 2: Wilcoxon Rank Sum Tests for Identity and Emotions Scores for Candidate Neutral Articles, Compared to a Baseline (Selected article in bold).

\begin{tabular}{|c|c|c|c|c|c|c|c|c|c|c|c|c|c|}
\hline & \multicolumn{2}{|c|}{ Identity } & \multirow[b]{2}{*}{ Distressed } & \multirow[b]{2}{*}{ Afraid } & \multirow[b]{2}{*}{ Upset } & \multirow[b]{2}{*}{ Scared } & \multicolumn{2}{|c|}{ Emotions } & \multirow[b]{2}{*}{ Proud } & \multirow[b]{2}{*}{ Strong } & \multirow[b]{2}{*}{ Inspired } & \multirow[b]{2}{*}{ Excited } & \multirow[b]{2}{*}{$n$} \\
\hline & American & Party & & & & & Nervous & Enthusiastic & & & & & \\
\hline \multicolumn{14}{|c|}{ Neutral primes (compared to baseline) } \\
\hline Alaska & 0.731 & 0.144 & 0.253 & $0.069^{*}$ & 0.128 & 0.207 & $0.007^{* * *}$ & 0.109 & $0.094^{*}$ & $0.009^{* * *}$ & $0.048^{* *}$ & $0.034^{* *}$ & 76 \\
\hline Cave & 0.513 & 0.178 & $0.072^{*}$ & 0.103 & 0.282 & 0.231 & $0.043^{* *}$ & 0.213 & $0.051^{*}$ & $0.023^{* *}$ & 0.719 & 0.713 & 73 \\
\hline Dog Show & 0.202 & 0.309 & $0.005^{* * *}$ & $0.002^{* * *}$ & $0.017^{* *}$ & $0.004^{* * *}$ & $0.003^{* * *}$ & $0.034^{* *}$ & $0.014^{* *}$ & $0.054^{*}$ & $0.018^{* *}$ & $0.006^{* * *}$ & 77 \\
\hline Ethiopian Airline & 0.829 & 0.745 & $0.013^{* *}$ & 0.480 & $0.011^{* *}$ & 0.935 & 0.442 & $0.001^{* * *}$ & $0.006^{* * *}$ & $0.026^{* *}$ & $0.025^{* *}$ & $0.001^{* * *}$ & 76 \\
\hline Luke Perry & 0.498 & 0.178 & 0.253 & $0.050^{*}$ & 0.976 & 0.128 & $0.060^{*}$ & $0.000^{* * *}$ & $0.000^{* * *}$ & $0.001^{* * *}$ & $0.000^{* * *}$ & $0.000^{* * *}$ & 73 \\
\hline Lunar New Year & 0.919 & $0.094^{*}$ & 0.558 & 0.103 & 0.255 & $0.039^{* *}$ & $0.039^{* *}$ & $0.003^{* * *}$ & $0.003^{* * *}$ & $0.009^{* * *}$ & $0.007^{* * *}$ & $0.005^{* * *}$ & 73 \\
\hline Mozambique & 0.421 & 0.172 & $0.021^{* *}$ & 0.666 & $0.026^{* *}$ & 0.665 & 0.345 & $0.000^{* * *}$ & $0.000^{* * *}$ & $0.008^{* * *}$ & $0.005^{* * *}$ & $0.001^{* * *}$ & 74 \\
\hline Myanmar & 0.204 & $0.047^{* *}$ & 0.147 & 0.814 & $0.034^{* *}$ & 0.549 & 0.743 & $0.000^{* * *}$ & $0.000^{* * *}$ & $0.003^{* * *}$ & $0.000^{* * *}$ & $0.000^{* * *}$ & 70 \\
\hline New Species & 0.717 & 0.782 & 0.318 & 0.983 & 0.207 & 0.477 & 0.194 & 0.293 & 0.318 & 0.815 & 0.565 & 0.703 & 76 \\
\hline New Zealand & 0.980 & 0.259 & $0.000^{* * *}$ & $0.012^{* *}$ & $0.000^{* * *}$ & $0.018^{* *}$ & 0.333 & $0.001^{* * *}$ & $0.000^{* * *}$ & $0.002^{* * *}$ & $0.000^{* * *}$ & $0.000^{* * *}$ & 79 \\
\hline Oscars & 0.827 & 0.117 & $0.033^{* *}$ & $0.054^{*}$ & 0.316 & 0.101 & $0.015^{* *}$ & $0.003^{* * *}$ & $0.001^{* * *}$ & $0.002^{\text {*** }}$ & $0.006^{* * *}$ & $0.075^{*}$ & 73 \\
\hline Vienna & 0.948 & 0.357 & $0.021^{* *}$ & $0.002^{* * *}$ & $0.017^{* e ́}$ & $0.022^{* *}$ & $0.015^{* *}$ & $0.015^{* *}$ & $0.014^{* *}$ & $0.025^{* *}$ & $0.076^{*}$ & $0.035^{* *}$ & 77 \\
\hline
\end{tabular}

questions designed to determine whether respondents suspected the articles had been edited of fabricated. We received no indications from respondents that they suspected such editing or manipulation.

Our analysis suggested the best "neutral" prime was an article titled "Stone in African cave boasts oldest-known human drawing" (Table 2), shown in Figure 7. The article focused on details of an archaeological excavation in Blombos Cave, near the Indian ocean. A link to the full text of this article is available here. To select the ingroup prime for each candidate article, we compared self-reported importance of being American of MTurkers after reading the article with the levels recorded among respondents randomly selected to read the candidate neutral article. We found only one article that effectively primed patriotism by generating a significant difference in self-reported American identity among Republicans and Democrats, using Wilcoxon rank sum test (Table 3). The article was entitled "America celebrates July 4th with hot dogs, banners and barbecues" and discussed Fourth of July celebrations in various sites throughout the U.S., including both cities with a large population of Democrats (e.g., Austin, Texas) and Republicans (e.g., Gainseville, Florida). A similar article was used to prime patriotic responses in a previous study (34). A link to the full text of the patriotic article we used in our 
Table 3: Wilcoxon Rank Sum Tests for Identity and Emotions Scores for Patriotic, Compared to Neutral Articles (selected article in bold).

\begin{tabular}{|c|c|c|c|c|c|c|c|c|c|c|c|c|c|}
\hline & \multicolumn{2}{|c|}{ Identity } & \multirow[b]{2}{*}{ Distressed } & \multirow[b]{2}{*}{ Afraid } & \multirow[b]{2}{*}{ Upset } & \multirow[b]{2}{*}{ Scared } & \multicolumn{2}{|c|}{ Emotions } & \multirow[b]{2}{*}{ Proud } & \multirow[b]{2}{*}{ Strong } & \multirow[b]{2}{*}{ Inspired } & \multirow[b]{2}{*}{ Excited } & \multirow[b]{2}{*}{$n$} \\
\hline & American & Party & & & & & Nervous & Enthusiastic & & & & & \\
\hline \multicolumn{14}{|c|}{ Ingroup primes (compared to pooled neutral primes) } \\
\hline Alabama & 0.571 & 0.532 & $0.001^{* * *}$ & $0.001^{* * *}$ & $0.007^{* * *}$ & $0.006^{* * *}$ & $0.000^{* * *}$ & 0.682 & 0.570 & 0.158 & 0.689 & 0.823 & 177 \\
\hline D-Day & 0.161 & 0.106 & 0.101 & $0.057^{*}$ & $0.065^{*}$ & $0.024^{* *}$ & $0.036^{* *}$ & 0.912 & $0.000^{* * *}$ & 0.625 & 0.226 & 0.468 & 180 \\
\hline Economy & 0.114 & 0.246 & $0.032^{* *}$ & 0.152 & $0.013^{* *}$ & 0.207 & 0.639 & 0.885 & 0.806 & 0.448 & 0.121 & 0.627 & 182 \\
\hline Gold Medals & 0.825 & 0.634 & 0.239 & 0.119 & $0.013^{* *}$ & 0.432 & 0.279 & $0.013^{* *}$ & $0.000^{* * *}$ & $0.090^{*}$ & $0.002^{* * *}$ & $0.026^{* *}$ & 179 \\
\hline Hot Dog & $0.073^{*}$ & 0.845 & 0.134 & 0.165 & $0.044^{* *}$ & 0.658 & 0.226 & $0.011^{* *}$ & $0.000^{* * *}$ & $0.028^{* *}$ & $0.012^{* *}$ & $0.033^{* *}$ & 179 \\
\hline July 4 & 0.990 & 0.241 & $0.046^{* *}$ & 0.300 & $0.057^{*}$ & 0.153 & 0.374 & $0.036^{* *}$ & $0.028^{* *}$ & 0.149 & $0.059^{*}$ & 0.244 & 183 \\
\hline Memorial Day & 0.636 & 0.945 & 0.389 & 0.162 & 0.128 & 0.188 & 0.223 & 0.222 & 0.525 & 0.631 & 0.259 & 0.123 & 178 \\
\hline Pyongyang & 0.913 & 0.174 & $0.025^{* *}$ & $0.077^{*}$ & $0.006^{* * *}$ & 0.319 & 0.556 & $0.081^{*}$ & $0.005^{\text {*** }}$ & 0.300 & 0.215 & $0.099^{*}$ & 180 \\
\hline Super Soldiers & 0.776 & 0.322 & 0.237 & 0.129 & 0.112 & 0.782 & 0.602 & $0.047^{* *}$ & $0.051^{*}$ & $0.073^{*}$ & $0.011^{* *}$ & $0.053^{*}$ & 179 \\
\hline Thanksgiving & 0.769 & 0.828 & $0.015^{* *}$ & 0.103 & $0.050^{*}$ & 0.145 & $0.051^{*}$ & 0.853 & 0.208 & 0.909 & 0.704 & 0.284 & 185 \\
\hline Tornados & 0.161 & 0.923 & $0.007^{* * *}$ & $0.076^{*}$ & $0.012^{* *}$ & $0.034^{* *}$ & $0.003^{* * *}$ & 0.262 & $0.071^{*}$ & 0.736 & 0.114 & 0.189 & 185 \\
\hline Veterans & 0.211 & 0.837 & $0.003^{* * *}$ & 0.963 & 0.115 & 0.804 & 0.260 & 0.539 & 0.710 & 0.824 & 0.861 & 0.739 & 178 \\
\hline
\end{tabular}

study is available here.

Selecting the article that created an equally strong sense of threat or fear among both Republicans and Democrats proved more challenging. In our initial round of testing, we discovered no suitable article - though the issue was mostly related to the level of threat experienced by respondents, not the consistency of this feeling across members of both parties. This led us to select four articles for a second round of pre-testing, run on July 18th, 2020, with an expanded sample conducted on Qualtrics as well as a small sample that was recruited to view the article on our study's main study platform. We used this second round of pre-testing to get more precise estimates of the identification measures described above and to assess the viability of the articles in the context of the experimental platform. To ensure that our respondents would feel sufficiently threatened, we also created and tested a new common enemy prime by combining content from three news stories from Reuters about possible threats from Iran, China, and Russia into a single article entitled "U.S.-Iran tensions rise among downing of U.S. Military Drone, China, Russia affirm Tehran's right to sovereignty.” By combining real-world news stories, the article discusses a scenario where Iran has shot down a U.S. drone, thereby raising fears of a military confrontation; meanwhile, the article suggests that China and Russia both 
Table 4: Wilcoxon Rank Sum Tests for Identity and Emotions Scores for Outgroup Articles (selected article in bold).

\begin{tabular}{|c|c|c|c|c|c|c|c|c|c|c|c|c|c|}
\hline & \multicolumn{2}{|c|}{ Identity } & \multirow[b]{2}{*}{ Distressed } & \multirow[b]{2}{*}{ Afraid } & \multirow[b]{2}{*}{ Upset } & \multirow[b]{2}{*}{ Scared } & \multicolumn{2}{|c|}{ Emotions } & \multirow[b]{2}{*}{ Proud } & \multirow[b]{2}{*}{ Strong } & \multirow[b]{2}{*}{ Inspired } & \multirow[b]{2}{*}{ Excited } & \multirow[b]{2}{*}{$n$} \\
\hline & American & Party & & & & & Nervous & Enthusiastic & & & & & \\
\hline \multicolumn{14}{|l|}{ Outgroup primes } \\
\hline \multicolumn{14}{|c|}{ First pre-test (compared to pooled neutral primes) } \\
\hline _ Rise and fall & 0.608 & 0.234 & 0.115 & 0.745 & 0.963 & 0.997 & 0.848 & 0.539 & 0.915 & 0.550 & 0.426 & 0.122 & 178 \\
\hline _ Organ harvesting & 0.657 & 0.140 & $0.002^{* * *}$ & $0.016^{* *}$ & $0.001^{* * *}$ & $0.009^{* * *}$ & $0.006^{* * *}$ & $0.059^{*}$ & 0.152 & 0.942 & 0.169 & $0.059^{*}$ & 181 \\
\hline Slavery & $0.064^{*}$ & 0.858 & $0.008^{* * *}$ & 0.982 & $0.000^{* * *}$ & 0.828 & 0.526 & $0.000^{* * *}$ & $0.001^{* * *}$ & $0.009^{* * *}$ & $0.001^{* * *}$ & $0.003^{* * *}$ & 182 \\
\hline Defeat & 0.230 & 0.486 & 0.436 & 0.594 & 0.867 & 0.522 & 0.275 & 0.512 & 0.853 & 0.576 & 0.298 & 0.843 & 177 \\
\hline _ Iraq & 0.406 & 0.947 & 0.188 & $0.058^{*}$ & 0.746 & 0.254 & $0.099^{*}$ & $0.005^{* * *}$ & $0.022^{* *}$ & $0.065^{*}$ & $0.073^{*}$ & 0.121 & 176 \\
\hline _ Cyber attack & 0.364 & 0.724 & 0.849 & 0.480 & 0.751 & 0.399 & 0.781 & 0.783 & 0.767 & 0.746 & 0.275 & 0.110 & 179 \\
\hline _ Homegrown & $0.074^{*}$ & 0.673 & 0.204 & 0.211 & 0.437 & 0.309 & $0.061^{*}$ & 0.619 & 0.756 & 0.145 & 0.182 & 0.169 & 176 \\
\hline _ Palmyra & 0.718 & 0.281 & $0.024^{* *}$ & 0.293 & $0.017^{* *}$ & $0.077^{*}$ & 0.217 & 0.356 & 0.327 & 0.637 & 0.202 & 0.975 & 181 \\
\hline \multicolumn{14}{|l|}{ Iran: } \\
\hline _ Gulf & 0.472 & 0.354 & 0.976 & 0.593 & 0.540 & 0.812 & 0.447 & 0.619 & 0.203 & 0.265 & 0.122 & 0.179 & 180 \\
\hline _ Death to US & 0.877 & 0.646 & 0.419 & 0.189 & 0.420 & 0.319 & 0.129 & 0.508 & 0.430 & 0.981 & 0.189 & 0.569 & 181 \\
\hline \multicolumn{14}{|l|}{ China: } \\
\hline _ Trade War & 0.373 & 0.604 & 0.315 & 0.928 & 0.816 & 0.633 & 0.879 & $0.049^{* *}$ & $0.033^{* *}$ & 0.360 & 0.188 & 0.257 & 178 \\
\hline _ Cyber attack & 0.739 & 0.416 & $0.007^{* * *}$ & $0.033^{* *}$ & $0.014^{* *}$ & $0.006^{* * *}$ & $0.008^{* * *}$ & $0.046^{* *}$ & $0.011^{* *}$ & 0.213 & $0.006^{* * *}$ & $0.037^{* *}$ & 179 \\
\hline \multicolumn{14}{|l|}{ Russia: } \\
\hline _ Weapons & 0.218 & 0.972 & $0.024^{* *}$ & $0.003^{* * *}$ & 0.302 & $0.000^{* * * *}$ & $0.005^{* * *}$ & $0.009^{* * *}$ & $0.006^{* * *}$ & $0.068^{*}$ & $0.004^{* * *}$ & $0.057^{*}$ & 177 \\
\hline _ Cuba help & 0.742 & 0.251 & 0.908 & $0.036^{* *}$ & 0.420 & $0.039^{* *}$ & $0.007^{* * *}$ & 0.553 & 0.552 & 0.279 & 0.689 & 0.495 & 178 \\
\hline \multicolumn{14}{|l|}{ Others: } \\
\hline _ Al Qaeda & 0.170 & 0.351 & 0.466 & 0.827 & 0.519 & 0.277 & 0.517 & $0.005^{* * *}$ & 0.123 & 0.229 & $0.007^{* * *}$ & $0.018^{* *}$ & 179 \\
\hline _ Pearl Harbor & 0.378 & 0.274 & 0.659 & 0.235 & 0.179 & 0.461 & 0.272 & $0.045^{* *}$ & $0.018^{* *}$ & 0.612 & 0.740 & $0.048^{* *}$ & 179 \\
\hline _ Cuba & 0.916 & 0.501 & 0.959 & 0.937 & 0.609 & 0.737 & 0.751 & $0.081^{*}$ & 0.677 & 0.325 & 0.416 & 0.545 & 178 \\
\hline \multicolumn{14}{|c|}{ Second pre-test (compared to selected neutral prime) } \\
\hline Organ harvesting & 0.859 & $0.003^{* *}$ & $0.000^{* * *}$ & $0.000^{* * *}$ & $0.000^{* * *}$ & $0.000^{* * *}$ & $0.000^{* * *}$ & $0.000^{* * *}$ & $0.000^{* * *}$ & 0.309 & $0.000^{* * *}$ & $0.000^{* * *}$ & 229 \\
\hline Rise and fall & 0.264 & $0.048^{* *}$ & $0.000^{* * *}$ & $0.012^{* *}$ & $0.000^{* * *}$ & $0.012^{* *}$ & $0.000^{* * *}$ & $0.000^{* * *}$ & $0.001^{* * *}$ & 0.465 & $0.000^{* * *}$ & $0.000^{* * *}$ & 221 \\
\hline Homegrown & 0.410 & 0.192 & $0.000^{* * *}$ & $0.000^{* * *}$ & $0.000^{* * *}$ & $0.000^{* * *}$ & $0.000^{* * *}$ & $0.000^{* * *}$ & $0.000^{* * *}$ & $0.023^{* *}$ & $0.000^{* * *}$ & $0.000^{* * *}$ & 229 \\
\hline Superenemy & $0.040^{* *}$ & 0.849 & $0.000^{* * *}$ & $0.000^{* * *}$ & $0.000^{* * *}$ & $0.000^{* * *}$ & $0.000^{* * *}$ & $0.000^{* * *}$ & $0.000^{* * * *}$ & $0.025^{* *}$ & $0.000^{* * *}$ & $0.000^{* * *}$ & 226 \\
\hline
\end{tabular}

independently sided with Iran in the conflict, thus suggesting the growing threat of an alliance between all three enemies of the U.S. We found that this article significantly primed American identity compared to the neutral article (Table 5). Therefore, we selected it as our common enemy prime. A link to the full text of this article is available here.

Through two-way ANOVA, reported in Table 5, we further report that reactions to the selected primes do not differ by partisanship. In fact, data from our rounds of pre-tests show that the interaction between a dummy for Republicans and a Treatment dummy indicating the priming does not have a statistically significant effect on American identity, for both the patriotic and the enemy prime ( $p=0.32$ and 0.93 respectively). This reassures us that any asymmetric reactions to the priming are not driven by underlying characteristics of the treatment. In Table 
Table 5: Two-way ANOVA comparing mean Identity Scores for selected articles, by partisanship and treatment.

\begin{tabular}{|c|c|c|c|}
\hline \multirow{2}{*}{\multicolumn{3}{|c|}{$\begin{array}{ll}\text { Selected articles (compared to selected neutral prime) } \\
\end{array}$}} & "n \\
\hline & & & \\
\hline $\begin{array}{l}\text { Patriotic prime } \\
\text { _ Hot dog x Republican }\end{array}$ & 1.01 & 0.11 & 150 \\
\hline $\begin{array}{l}\text { Enemy prime } \\
\text { _ Superenemy x Republican }\end{array}$ & 0.01 & 0.22 & 173 \\
\hline $\begin{array}{l}\text { Iran: } \\
\text { _ Gulf x Republican } \\
\text { _ Death to US x Republican }\end{array}$ & $\begin{array}{l}0.20 \\
0.26\end{array}$ & $\begin{array}{l}0.65 \\
1.22\end{array}$ & $\begin{array}{l}88 \\
90\end{array}$ \\
\hline $\begin{array}{l}\text { China: } \\
\text { _ Trade x Republican } \\
\text { _ Tech race x Republican } \\
\text { _ Cyber attack x Republican }\end{array}$ & $\begin{array}{l}1.36 \\
0.23 \\
3.42^{*}\end{array}$ & $\begin{array}{l}0.25 \\
0.11 \\
2.28\end{array}$ & $\begin{array}{l}87 \\
88 \\
93\end{array}$ \\
\hline $\begin{array}{l}\text { Russia: } \\
\text { - Weapons x Republican } \\
\text { _ Cuba help x Republican }\end{array}$ & $\begin{array}{l}0.41 \\
0.05\end{array}$ & $\begin{array}{l}0.03 \\
0.38\end{array}$ & $\begin{array}{l}90 \\
90\end{array}$ \\
\hline
\end{tabular}

5, we also leverage seven pre-test primes, on the three enemies portrayed in the 'Superenemy' article (Iran, China and Russia), to test for the existence of asymmetric partisan reactions to each of these enemies. We do not find any evidence of asymmetric reactions of Republican versus Democrats to any of the treatments concerning Iran and Russia and for two out of the three articles concerning China, while we found a statistically significant interaction between the republican dummy and the treatment Cyber Attack (an article on Chinese cyber warfare) on the dependent variable American identity $(p=0.08)$.

\subsection{Post-Stratification Analysis of Updates}

In this section we explain the methodology we used to obtain results in Figures 2, 3 and 4. In both post-stratification and other robustness models, the dependent variable is the amount the participants updated their estimates in response to the first estimate made by the bot impersonating a member of the opposing party. If the participant updates their first estimate to move closer to the bot's estimate, the dependent variable is positive. In contrast, if the participant moves away from the bot, the dependent variable is negative. The equation below formalizes the definition of our dependent variable: 


$$
y_{\mathrm{t}}= \begin{cases}+\left|x_{\mathrm{p}, \mathrm{t}+1}-x_{\mathrm{p}, \mathrm{t}}\right| & \text { if }\left|x_{\mathrm{p}, \mathrm{t}+1}-x_{\mathrm{b}, \mathrm{t}}\right| \leq\left|x_{\mathrm{p}, \mathrm{t}}-x_{\mathrm{b}, \mathrm{t}}\right| \\ -\left|x_{\mathrm{p}, \mathrm{t}+1}-x_{\mathrm{p}, \mathrm{t}}\right| & \text { otherwise }\end{cases}
$$

where $y_{\mathrm{t}}$ is the dependent variable corresponding to $\mathrm{t}^{\text {th }}$ update and $x_{\mathrm{p}, \mathrm{t}}$ and $x_{\mathrm{b}, \mathrm{t}}$ correspond to the player's and the bot's estimates in round $t$ respectively. We could perform the analysis with the dependent variable (i.e. updates) that corresponds to different rounds, but for our main results, we only focus on the dependent variable corresponding to the first update, when $t=1$. We made this decision because the majority of updates happen in the second round as the information concerning the bot's estimate is mostly conveyed in that round and the political affiliation of the bot is redundant thereafter.

To generate our main results, we estimated the mean update toward the bot, accounting for the variation in composition of participants by gender, political knowledge, their initial estimate and whether they correctly identified the political affiliation of the other user on the platform within each prime condition. Effectively, we treated the full sample of participants in our study as the reference population and used post-stratification to compute mean updates that have controlled for variation in strata size across treatments.

Different strata were defined for each possible combination of control variables mentioned above. Next, we discuss the rationale for controlling for each of these variables. A key assumption of our research design is that respondents realize they are collaborating with a member of the other party during the estimation task in our online platform. Though we used strong visual cues to communicate this to respondents, our exit-survey also included a question that asked respondents whether they remembered the party affiliation of the other user on the online platform. Hence, our post-stratification analysis used a binary indicator of whether respondents correctly identified the political affiliation of the other user (i.e. the bot) on the platform, as one dimension of each strata definition.

Because the initial estimates of our bots were programmed to always be 50 percentage points 
plus a small random noise away from our respondents (on a 0-100 scale), this response may be more or less credible depending upon the respondent's initial guess. For example, respondents who guessed that only $10 \%$ of recent immigrants hold a college degree would view an estimate of $60 \%$ from the bot, which would be more plausible than another respondent who guessed $48 \%$, which would provoke a guess of $98 \%$ from the bot. To control for the initial estimates, we converted respondents' first estimates to categorical variables by binning them into intervals of length 25, and used this four-level categorical variables as another dimension of strata definition.

The exit survey included a question about which party has a majority of seats in the Senate. This question was used to test whether the respondent had high political knowledge. Our post-stratification estimate thus includes a binary indicator of whether the respondents correctly answered this question as another factor in strata definition. Finally, there is some evidence in the literature on the existence of the gender gap in political partisanship (35). Therefore, we control for the gender of the respondent as a binary variable in our analysis.

The equation below shows how the mean update within each prime treatment can be estimated using post-stratification:

$$
\begin{aligned}
\bar{Y}_{t} & =\sum_{s} \frac{N_{s}}{N} \bar{y}_{t, s} \\
& =\sum_{s} \frac{N_{s}}{N} \frac{1}{n_{t, s}} \sum_{i \in P_{t, s}} y_{i}
\end{aligned}
$$

where $\bar{Y}_{t}$ is the post-stratified estimate of mean update in prime treatment $t, N_{s}$ is the number of participants in strata $s$ across all treatments, $N$ is the total number of participants across all primes treatments. $\bar{y}_{t, s}$ is the average update of participants in prime treatment $t$ and strata $s$. $P_{c, s}$ and $n_{c, s}$ are the set and size of such participants respectively, and finally $y_{i}$ is the amount participant $i$ updated their initial estimate after observing the bot's estimate. As noted above, the estimate $\bar{Y}_{t}$ treats all recruited participants as the reference population and weights the average of each strata based on frequency of that strata in the population. The point estimates from 
the equation above are shown in Figure 2. The point estimates shown in Figures 3 and 4 are computed in a similar fashion with the difference that $t$ would correspond to level of in-group favoritism or timing with respect to the assassination.

The variance of $\bar{Y}_{t}$ can be estimated using equation below (36):

$$
\widehat{\operatorname{Var}}\left(\bar{Y}_{t}\right) \approx \frac{N-n_{t}}{n_{t} N} \sum_{s} \frac{N_{s}}{N} S_{s, t}^{2}+\frac{N-n_{t}}{n_{t}^{2}(N-1)} \sum_{s} \frac{N-N_{s}}{N} S_{s, t}^{2}
$$

where $n_{t}$ is the number of participants in treatment $t$ and $S_{s, t}^{2}$ is the samples variance of updates in prime treatment $t$ and strata $s$. Given the estimate of variance above, we can construct confidence intervals as shown in Figures 2, 3 and 4 in the main text. We can further perform post-stratification adjusted t-tests to compare mean updates between various conditions. We used the R package survey (37) to perform the two sample t-tests between treatments.

To produce the results in Figure 3, we created a measure that describes how much Republicans identify with their own party or their in-group bias. More specifically, we calculated the difference between each respondent's in-group and out-group feeling thermometer. We then labeled those participants in the top 10th percentile of this measure as strongly partisan with high in-group bias and the remaining individuals as moderate partisans. The 10th percentile cutoff for Republicans in our data corresponds to 91 percentage points difference between feeling toward Republicans and feeling toward Democrats. The post-stratified difference between strong and moderate Republicans remains significant if we change the cutoff point to 20th or 30th percentiles of the measure of in-group bias described above, but as we increase this cutoff point the difference between the two groups becomes less noticeable.

An alternative method to measure the strength of partisanship is to use the raw measure of feeling toward in-group party. We can then treat the participants in top 10th percentile of this measure as strongly partisan and the rest as moderately partisan. The 10th percentile cutoff for Republican participants in our data corresponds to 99 out of 100 percentage points for feeling 




Figure 12: Amount of cooperation among Republican study participants across all prime conditions with a bot impersonating a Democrat during collaborative online task by an alternative measure for strength of partisanship. Vertical axis describes the post-stratified average belief update (in percentage points), where strata are defined by gender, political knowledge, the accuracy of initial guess, and awareness of bot's membership in the opposing party. Strong republicans are defined as those who are in the top 10th percentile of an in-group feeling thermometer measure. Error bars display $95 \%$ confidence intervals. $* \mathrm{p}<0.05$.

toward Republicans. As there is only about $50 \%$ overlap between these two different measures of strong partisanship (based on the aforementioned measure or feeling thermometers toward one's own party alone), we expect this alternative measure to act as a robustness check to our result based on the normalized feeling thermometer measure analyzed in the main text. Figure 12 shows the post-stratified difference between these two group of Republicans. The result from this alternative measure of partisan identification is similar to and verifies the results in Figure 3 in the main text.

\subsection{Robustness Checks for Main Models}

In this section, we report a series of regression models as robustness checks for Republicans (Table 6-7) and Democrats (Table 8-9). Similar to our main analysis with post-stratification, 
the dependent variable is the amount participants updated their estimates in response to the first estimate made by the bot impersonating a member of the opposing party. Throughout, we use the same or similar set of control variables as discussed above in section 1.4, namely gender, political knowledge, initial estimate and awareness of the other player's political affiliation.

\subsubsection{Model 1: Regression Model}

Model 1 utilizes exactly the same covariates as in the post-stratification method in Figure 2 among Republicans (Table 6) and Democrats (Table 8). This model includes binary indicators that describe the patriotic and common enemy primes and controlled for whether respondents correctly identify the political affiliation of the other user on the platform, the respondent's initial estimates, political knowledge, and gender. As these models show, the effect discussed in the main text of our article on Republicans is also significant in this regression model.

\subsubsection{Model 2: Manipulation Check}

Model 2 reports the updating behavior among Republicans (Table 6) and Democrats (Table 8) on controls for the manipulation check. This model only includes binary indicators that describe the patriotic and common enemy primes, and a binary indicator of whether respondents correctly identified the political affiliation of the other user on the platform. The effect discussed in the main text remains with the manipulation check as the only control variable.

\subsubsection{Models 3 \& 4: Sensitivity of Results to Respondent's Initial Estimate}

Models 3 and 4 assess the sensitivity of our findings to heterogeneity in the respondents' initial estimates, as shown in Table 6 for Republicans and Table 8 for Democrats. In our main model, we use 4 bins to distinguish between respondents' initial estimates. In the current models we also control for (1) 10 bins; and (2) the distance of the respondent's initial response to 50.50 is chosen since this is the distance between the bot and the respondent's first response. As 
these models show, the effect discussed in the main text of our article is also significant in these alternative models.

\subsubsection{Model 5: Pre-Existing Knowledge of Issue in Estimation Task}

In our study's exit-survey, we asked our participants whether they were familiar with the issue in the estimation task. We collected this measure in order to determine whether people with more knowledge about the issue may be less likely to update their estimates in response to the bot regardless of priming condition or political party. Model 5 adds a binary indicator of familiarity with the issue, showing that the inclusion of this additional indicator does not substantively alter the results we report in the main text. The results are shown in Table 7 for Republicans and Table 9 for Democrats.

\subsubsection{Model 6: Age Effects}

There is some evidence in the scholarly literature on political polarization that political beliefs become more resistant to change across the life course. For this reason, we included the continuous variable of respondent's age as another control that we report in Model 6, with Republicans in Table 7 and Democrats in Table 9. Once again, the results we report in the main text of our article hold despite the inclusion of this additional indicator.

\subsubsection{Model 7: Variation in Bot Behavior}

In order to capture real-world variation in how members of opposing parties might interact with each other on our platform, our study randomized respondents to perform the estimation with a "friendly" bot or a "stubborn bot". While the former always updated towards the respondent's estimate, the latter held fast to its own initial estimate. To examine whether the behavior of the bot interacts with our treatment effects, Model 7 in Table 7 and Table 9 controls for the type of bot each respondent interacted with within each prime. We observed no significant effect of the 
bot type on the first update and the main effects of the common enemy prime remain consistent among Republicans, as before. Note that we would not expect a difference in the first update in response to the bot behavior, since the participants need to observe at least two bot estimates to infer anything about its behavior.

\subsubsection{Model 8: Inconsistent Reporting of Party Identification}

Because we collected respondents' political identification from the panel data originally used to identify respondents as well as on the platform itself, we were able to identify respondents who inconsistently reported their party identification. Though it is possible that some respondents changed political parties in the interim period, it is considerably more likely that these respondents were either responding expressively, or were not paying attention to the online platform's onboarding questions. As an additional robustness check, Model 8 removes these respondents from the data, producing results that are nearly identical to those we report in the main text of our article. The results are shown in Table 7 for Republicans and Table 9 for Democrats.

\subsection{Robustness Check for Findings about Strong Partisans}

As an additional robustness check for the findings reported in Figure 3 of the main text, we employ regression models with variations on the number of bins. Similar to the results we reported about the effect of partisanship using two different measures of party identification in Figures 3 and 12, Table 10 also shows that the effect of partisanship is consistently negative and significant for our two different measures of in-group bias. The effect is stronger with 10 bins in the initial estimate than 4 bins, however.

\subsection{Robustness Check for the Effect of Iran Crisis}

Table 11 presents a robustness check on the results reported in Figure 4 in the main text of our article. The binary indicator reported in Table 11 is an indicator for whether the experiment 
Table 6: Robustness Check on Republicans' Updates: Model 1 - 4

\begin{tabular}{|c|c|c|c|c|}
\hline & \multicolumn{4}{|c|}{ Dependent variable: first update } \\
\hline & Model 1 & Model 2 & Model 3 & Model 4 \\
\hline Intercept & $\begin{array}{c}15.691^{* * *} \\
(2.131)\end{array}$ & $\begin{array}{c}12.534^{* * *} \\
(1.586)\end{array}$ & $\begin{array}{l}15.808^{*} \\
(8.743)\end{array}$ & $\begin{array}{c}15.649^{* * *} \\
(2.311)\end{array}$ \\
\hline Patriotic prime & $\begin{array}{c}-0.306 \\
(1.343)\end{array}$ & $\begin{array}{c}-0.276 \\
(1.314)\end{array}$ & $\begin{array}{l}-0.028 \\
(1.332)\end{array}$ & $\begin{array}{c}-0.241 \\
(1.347)\end{array}$ \\
\hline Common enemy prime & $\begin{array}{c}-3.081^{* *} \\
(1.373)\end{array}$ & $\begin{array}{c}-2.816^{* *} \\
(1.335)\end{array}$ & $\begin{array}{c}-2.898^{* *} \\
(1.364)\end{array}$ & $\begin{array}{c}-2.891^{* *} \\
(1.375)\end{array}$ \\
\hline Manipulation check $(1=\mathrm{yes}, 0=\mathrm{no})$ & $\begin{array}{l}-1.984 \\
(1.522)\end{array}$ & $\begin{array}{l}-2.232 \\
(1.479)\end{array}$ & $\begin{array}{l}-1.871 \\
(1.51)\end{array}$ & $\begin{array}{l}-2.009 \\
(1.525)\end{array}$ \\
\hline Male $(1=$ yes, $0=$ no $)$ & $\begin{array}{l}-1.593 \\
(1.122)\end{array}$ & & $\begin{array}{l}-1.503 \\
(1.118)\end{array}$ & $\begin{array}{l}-1.568 \\
(1.124)\end{array}$ \\
\hline Respondent's initial estimate $[25,50)$ & $\begin{array}{l}-0.517 \\
(1.185)\end{array}$ & & & \\
\hline Respondent's initial estimate $[50,75)$ & $\begin{array}{l}3.233^{*} \\
(1.88)\end{array}$ & & & \\
\hline Respondent's initial estimate $[75,100]$ & $\begin{array}{c}5.891 \\
(5.018)\end{array}$ & & & \\
\hline Respondent's initial estimate $[0,10)$ & & & $\begin{array}{l}-2.164 \\
(8.625)\end{array}$ & \\
\hline Respondent's initial estimate $[10,20)$ & & & $\begin{array}{l}-0.514 \\
(8.525)\end{array}$ & \\
\hline Respondent's initial estimate $[20,30)$ & & & $\begin{array}{c}1.854 \\
(8.535)\end{array}$ & \\
\hline Respondent's initial estimate $[30,40)$ & & & $\begin{array}{l}-1.367 \\
(8.547)\end{array}$ & \\
\hline Respondent's initial estimate $[40,50)$ & & & $\begin{array}{l}-2.115 \\
(8.599)\end{array}$ & \\
\hline Respondent's initial estimate $[50,60)$ & & & $\begin{array}{l}-2.763 \\
(8.927)\end{array}$ & \\
\hline Respondent's initial estimate $[60,70)$ & & & $\begin{array}{c}3.66 \\
(8.743)\end{array}$ & \\
\hline Respondent's initial estimate $[70,80)$ & & & $\begin{array}{l}17.483^{*} \\
(9.593)\end{array}$ & \\
\hline Respondent's initial estimate $[90,100]$ & & & $\begin{array}{c}3.063 \\
(14.705)\end{array}$ & \\
\hline Respondent's initial estimate: distance to 50 & & & & $\begin{array}{c}0.013 \\
(0.045)\end{array}$ \\
\hline High political knowledge $(1=$ yes, $0=$ no $)$ & $\begin{array}{c}-3.356^{* *} \\
(1.49) \\
\end{array}$ & & $\begin{array}{c}-3.485^{* *} \\
(1.478) \\
\end{array}$ & $\begin{array}{c}-3.529^{* *} \\
(1.489) \\
\end{array}$ \\
\hline Observations & 485 & 512 & 485 & 485 \\
\hline $\mathrm{R} 2$ & 0.044 & 0.014 & 0.085 & 0.034 \\
\hline Adjusted R2 & 0.028 & 0.009 & 0.058 & 0.022 \\
\hline Residual Std. Error & $12.101(\mathrm{df}=476)$ & $12.2(\mathrm{df}=508)$ & $11.916(\mathrm{df}=470)$ & $12.141(\mathrm{df}=478)$ \\
\hline F Statistic & $2.739^{* * *}(\mathrm{df}=8 ; 476)$ & $2.477^{*}(\mathrm{df}=3 ; 508)$ & $3.109^{* * *}(\mathrm{df}=14 ; 470)$ & $2.773^{* *}(\mathrm{df}=6 ; 478)$ \\
\hline
\end{tabular}


Table 7: Robustness Check on Republicans' Updates: Model 5 - 8

\begin{tabular}{|c|c|c|c|c|}
\hline & \multicolumn{4}{|c|}{ Dependent variable: first update } \\
\hline & Model 5 & Model 6 & Model 7 & Model 8 \\
\hline Intercept & $\begin{array}{c}15.084^{* * *} \\
(2.168)\end{array}$ & $\begin{array}{c}15.761^{* * *} \\
(3.008)\end{array}$ & $\begin{array}{c}15.453^{* * *} \\
(2.22)\end{array}$ & $\begin{array}{c}15.775^{* * *} \\
(2.166)\end{array}$ \\
\hline Patriotic prime & $\begin{array}{l}0.287 \\
(1.36)\end{array}$ & $\begin{array}{l}-0.454 \\
(1.355)\end{array}$ & $\begin{array}{c}-0.29 \\
(1.344)\end{array}$ & $\begin{array}{l}-0.437 \\
(1.359)\end{array}$ \\
\hline Common enemy prime & $\begin{array}{c}-3.081^{* *} \\
(1.387)\end{array}$ & $\begin{array}{c}-2.856^{* *} \\
(1.38)\end{array}$ & $\begin{array}{c}-3.055^{* *} \\
(1.376)\end{array}$ & $\begin{array}{c}-3.198^{* *} \\
(1.389)\end{array}$ \\
\hline Age & & $\begin{array}{l}-0.011 \\
(0.044)\end{array}$ & & \\
\hline Manipulation check ( $1=$ yes, $0=$ no) & $\begin{array}{c}-1.51 \\
(1.541)\end{array}$ & $\begin{array}{l}-2.41 \\
(1.53)\end{array}$ & $\begin{array}{l}-1.972 \\
(1.523)\end{array}$ & $\begin{array}{l}-2.019 \\
(1.538)\end{array}$ \\
\hline High issue knowledge $(1=\mathrm{yes}, 0=$ no $)$ & $\begin{array}{l}-0.263 \\
(1.475)\end{array}$ & & & \\
\hline Male $(1=$ yes, $0=$ no $)$ & $\begin{array}{l}-1.568 \\
(1.135)\end{array}$ & $\begin{array}{l}-1.579 \\
(1.14)\end{array}$ & $\begin{array}{l}-1.952^{*} \\
(1.124)\end{array}$ & $\begin{array}{l}-1.608 \\
(1.136)\end{array}$ \\
\hline Respondent's initial estimate $[25,50)$ & $\begin{array}{l}-0.165 \\
(1.195)\end{array}$ & $\begin{array}{l}-0.467 \\
(1.192)\end{array}$ & $\begin{array}{l}-0.524 \\
(1.186)\end{array}$ & $\begin{array}{c}-0.548 \\
(1.2)\end{array}$ \\
\hline Respondent's initial estimate $[50,75)$ & $\begin{array}{l}3.233^{*} \\
(1.872)\end{array}$ & $\begin{array}{c}3.42^{*} \\
(1.895)\end{array}$ & $\begin{array}{c}3.228^{*} \\
(1.881)\end{array}$ & $\begin{array}{l}3.218^{*} \\
(1.893)\end{array}$ \\
\hline Respondent's initial estimate $[75,100]$ & $\begin{array}{l}6.609 \\
(5.435)\end{array}$ & $\begin{array}{c}6.258 \\
(4.962)\end{array}$ & $\begin{array}{c}5.968 \\
(5.027)\end{array}$ & $\begin{array}{c}5.821 \\
(5.043)\end{array}$ \\
\hline High political knowledge $(1=$ yes, $0=$ no $)$ & $\begin{array}{c}-3.731^{* *} \\
(1.496)\end{array}$ & $\begin{array}{c}-2.52^{*} \\
(1.516)\end{array}$ & $\begin{array}{c}-3.349^{* *} \\
(1.492)\end{array}$ & $\begin{array}{c}-3.398^{* *} \\
(1.507)\end{array}$ \\
\hline Stubborn bot [reference: friendly bot] & & & $\begin{array}{c}0.427 \\
(1.103) \\
\end{array}$ & \\
\hline Observations & 469 & 467 & 485 & 478 \\
\hline $\mathrm{R} 2$ & 0.046 & 0.043 & 0.044 & 0.044 \\
\hline Adjusted R2 & 0.027 & 0.024 & 0.026 & 0.027 \\
\hline Residual Std. Error & $11.985(\mathrm{df}=459)$ & $11.947(\mathrm{df}=457)$ & $12.112(\mathrm{df}=475)$ & $12.157(\mathrm{df}=469)$ \\
\hline F Statistic & $2.44^{* *}(\mathrm{df}=9 ; 459)$ & $2.258^{* *}(\mathrm{df}=9 ; 457)$ & $2.447^{* * *}(\mathrm{df}=9 ; 475)$ & $2.67^{* * *}(\mathrm{df}=8 ; 469)$ \\
\hline
\end{tabular}


Table 8: Robustness Check on Democrats' Updates: Model 1 -4

\begin{tabular}{|c|c|c|c|c|}
\hline & \multicolumn{4}{|c|}{ Dependent variable: first update } \\
\hline & Model 1 & Model 2 & Model 3 & Model 4 \\
\hline Intercept & $\begin{array}{c}8.387^{* * *} \\
(2.302)\end{array}$ & $\begin{array}{c}7.053^{* * *} \\
(1.827)\end{array}$ & $\begin{array}{l}-3.628 \\
(6.659)\end{array}$ & $\begin{array}{l}3.823^{*} \\
(2.307)\end{array}$ \\
\hline Patriotic prime & $\begin{array}{l}-0.294 \\
(1.313)\end{array}$ & $\begin{array}{l}0.002 \\
(1.31)\end{array}$ & $\begin{array}{l}-0.348 \\
(1.321)\end{array}$ & $\begin{array}{l}-0.509 \\
(1.305)\end{array}$ \\
\hline Common enemy prime & $\begin{array}{c}1.054 \\
(1.327)\end{array}$ & $\begin{array}{c}1.061 \\
(1.303)\end{array}$ & $\begin{array}{c}1.11 \\
(1.336)\end{array}$ & $\begin{array}{l}1.096 \\
(1.321)\end{array}$ \\
\hline Manipulation check $(1=y e s, 0=$ no $)$ & $\begin{array}{c}2.682 \\
(1.814)\end{array}$ & $\begin{array}{c}2.154 \\
(1.778)\end{array}$ & $\begin{array}{c}2.621 \\
(1.813)\end{array}$ & $\begin{array}{c}2.482 \\
(1.804)\end{array}$ \\
\hline High issue knowledge $(1=\mathrm{yes}, 0=$ no $)$ & & & & \\
\hline Male $(1=$ yes, $0=$ no $)$ & $\begin{array}{c}0.898 \\
(1.077)\end{array}$ & & $\begin{array}{c}0.791 \\
(1.082)\end{array}$ & $\begin{array}{c}0.854 \\
(1.071)\end{array}$ \\
\hline Respondent's initial estimate $[25,50)$ & $\begin{array}{l}-2.097^{*} \\
(1.235)\end{array}$ & & & \\
\hline Respondent's initial estimate $[50,75)$ & $\begin{array}{c}-4.208^{* * *} \\
(1.532)\end{array}$ & & & \\
\hline Respondent's initial estimate $[75,100)$ & $\begin{array}{l}-3.015 \\
(4.034)\end{array}$ & & & \\
\hline Respondent's initial estimate $[0,10)$ & & & $\begin{array}{l}12.727^{*} \\
(6.834)\end{array}$ & \\
\hline Respondent's initial estimate $[10,20)$ & & & $\begin{array}{l}11.978^{*} \\
(6.314)\end{array}$ & \\
\hline Respondent's initial estimate $[20,30)$ & & & $\begin{array}{l}12.396^{*} \\
(6.313)\end{array}$ & \\
\hline Respondent's initial estimate $[30,40)$ & & & $\begin{array}{l}10.354 \\
(6.293)\end{array}$ & \\
\hline Respondent's initial estimate $[40,50)$ & & & $\begin{array}{c}8.214 \\
(6.334)\end{array}$ & \\
\hline Respondent's initial estimate $[50,60)$ & & & $\begin{array}{l}7.261 \\
(6.45)\end{array}$ & \\
\hline Respondent's initial estimate $[60,70)$ & & & $\begin{array}{c}9.724 \\
(6.449)\end{array}$ & \\
\hline Respondent's initial estimate $[70,80)$ & & & $\begin{array}{c}7.501 \\
(6.871)\end{array}$ & \\
\hline Respondent's initial estimate: distance to 50 & & & & $\begin{array}{c}0.152^{* * *} \\
(0.046)\end{array}$ \\
\hline High political knowledge ( $1=$ yes, $0=$ no $)$ & $\begin{array}{l}-0.283 \\
(1.455)\end{array}$ & & $\begin{array}{c}-0.27 \\
(1.461)\end{array}$ & $\begin{array}{c}-0.42 \\
(1.445)\end{array}$ \\
\hline Observations & 530 & 554 & 530 & 530 \\
\hline $\mathrm{R} 2$ & 0.022 & 0.004 & 0.034 & 0.028 \\
\hline Adjusted R2 & 0.007 & -0.001 & 0.01 & 0.017 \\
\hline Residual Std. Error & $12.357(\mathrm{df}=521)$ & $12.507(\mathrm{df}=550)$ & $12.34(\mathrm{df}=516)$ & $12.298(\mathrm{df}=523)$ \\
\hline F Statistic & $1.479(\mathrm{df}=8 ; 521)$ & $0.805(\mathrm{df}=3 ; 550)$ & $1.411(\mathrm{df}=13 ; 516)$ & $2.492^{* *}(\mathrm{df}=6 ; 523)$ \\
\hline
\end{tabular}


Table 9: Robustness Check on Democrats' Updates: Model 5 - 8

\begin{tabular}{|c|c|c|c|c|}
\hline & \multicolumn{4}{|c|}{ Dependent variable: first update } \\
\hline & Model 5 & Model 6 & Model 7 & Model 8 \\
\hline Intercept & $\begin{array}{l}3.823^{*} \\
(2.307)\end{array}$ & $\begin{array}{c}8.655^{* * *} \\
(2.341)\end{array}$ & $\begin{array}{c}11.227^{* * *} \\
(3.208)\end{array}$ & $\begin{array}{l}8.7^{* * *} \\
(2.361)\end{array}$ \\
\hline Patriotic prime & $\begin{array}{c}-0.294-0.004 \\
(1.325)\end{array}$ & $\begin{array}{l}-0.506 \\
(1.338)\end{array}$ & $\begin{array}{l}-0.281 \\
(1.314)\end{array}$ & $\begin{array}{l}-0.245 \\
(1.319)\end{array}$ \\
\hline Common enemy prime & $\begin{array}{c}1.054 \\
(1.351)\end{array}$ & $\begin{array}{c}0.923 \\
(1.361)\end{array}$ & $\begin{array}{l}1.073 \\
(1.329)\end{array}$ & $\begin{array}{l}1.372 \\
(1.333)\end{array}$ \\
\hline Age & & $\begin{array}{l}-0.063 \\
(0.053)\end{array}$ & & \\
\hline Manipulation check $(1=$ yes, $0=$ no $)$ & $\begin{array}{c}2.409 \\
(1.845)\end{array}$ & $\begin{array}{l}2.501 \\
(1.834)\end{array}$ & $\begin{array}{c}2.75 \\
(1.818)\end{array}$ & $\begin{array}{l}2.405 \\
(1.843)\end{array}$ \\
\hline High issue knowledge $(1=$ yes, $0=$ no $)$ & $\begin{array}{l}-1.447 \\
(1.419)\end{array}$ & & & \\
\hline Male ( $1=$ yes, $0=$ no $)$ & $\begin{array}{c}0.898 \\
(1.089)\end{array}$ & $\begin{array}{l}0.458 \\
(1.12)\end{array}$ & $\begin{array}{c}0.86 \\
(1.08)\end{array}$ & $\begin{array}{c}0.75 \\
(1.084)\end{array}$ \\
\hline Respondent's initial estimate $[25,50)$ & $\begin{array}{l}-2.299^{*} \\
(1.246)\end{array}$ & $\begin{array}{l}-2.167^{*} \\
(1.257)\end{array}$ & $\begin{array}{l}-2.142^{*} \\
(1.238)\end{array}$ & $\begin{array}{l}-2.347^{*} \\
(1.246)\end{array}$ \\
\hline Respondent's initial estimate $[50,75)$ & $\begin{array}{c}-4.639^{* * *} \\
(1.553)\end{array}$ & $\begin{array}{c}-4.155^{* * *} \\
(1.557)\end{array}$ & $\begin{array}{c}-4.214^{* * *} \\
(1.533)\end{array}$ & $\begin{array}{c}-4.218^{* * *} \\
(1.533)\end{array}$ \\
\hline Respondent's initial estimate $[75,100)$ & $\begin{array}{l}-3.102 \\
(4.018)\end{array}$ & $\begin{array}{l}-1.891 \\
(4.256)\end{array}$ & $\begin{array}{l}-3.189 \\
(4.047)\end{array}$ & $\begin{array}{c}-3.1 \\
(4.023)\end{array}$ \\
\hline High political knowledge $(1=$ yes, $0=$ no $)$ & $\begin{array}{l}-0.079 \\
(1.484)\end{array}$ & $\begin{array}{l}-0.158 \\
(1.478)\end{array}$ & $\begin{array}{l}-0.29 \\
(1.456)\end{array}$ & $\begin{array}{l}0.128 \\
(1.459)\end{array}$ \\
\hline Stubborn bot [reference: friendly bot] & & & $\begin{array}{l}-0.655 \\
(1.083)\end{array}$ & \\
\hline Observations & 514 & 510 & 530 & 520 \\
\hline $\mathrm{R} 2$ & 0.028 & 0.024 & 0.023 & 0.023 \\
\hline Adjusted R2 & 0.01 & 0.007 & 0.006 & 0.008 \\
\hline Residual Std. Error & $12.294(\mathrm{df}=504)$ & $12.381(\mathrm{df}=500)$ & $12.364(\mathrm{df}=520)$ & $12.313(\mathrm{df}=511)$ \\
\hline F Statistic & $1.595(\mathrm{df}=9 ; 504)$ & $1.379(\mathrm{df}=9 ; 500)$ & $1.354(\mathrm{df}=9 ; 520)$ & $1.504(\mathrm{df}=8 ; 511)$ \\
\hline
\end{tabular}




\section{Table 10: Robustness Check for the Strength of Partisanship as in Figure 3}

\begin{tabular}{|c|c|c|c|c|}
\hline & \multicolumn{4}{|c|}{ Dependent variable: first update } \\
\hline & $\begin{array}{l}\text { Republican's feel } \\
\text { (4 bins) }\end{array}$ & $\begin{array}{l}\text { Republican's feel } \\
\text { (10 bins })\end{array}$ & $\begin{array}{l}\text { In-group bias } \\
\text { (4 bins) }\end{array}$ & $\begin{array}{l}\text { In-group bias } \\
\text { (10 bins) }\end{array}$ \\
\hline Intercept & $\begin{array}{c}15.318^{* * *} \\
(2.031)\end{array}$ & $\begin{array}{l}14.663^{*} \\
(8.735)\end{array}$ & $\begin{array}{c}15.347^{* * *} \\
(2.03)\end{array}$ & $\begin{array}{l}16.783^{*} \\
(8.808)\end{array}$ \\
\hline Manipulation check $(1=\mathrm{yes}, 0=$ no $)$ & $\begin{array}{l}-2.012 \\
(1.528)\end{array}$ & $\begin{array}{l}-1.976 \\
(1.516)\end{array}$ & $\begin{array}{l}-2.073 \\
(1.529)\end{array}$ & $\begin{array}{l}-2.042 \\
(1.518)\end{array}$ \\
\hline Male $(1=$ yes, $0=$ no $)$ & $\begin{array}{l}-1.908^{*} \\
(1.121)\end{array}$ & $\begin{array}{l}-1.807 \\
(1.116)\end{array}$ & $\begin{array}{l}-2.035^{*} \\
(1.125)\end{array}$ & $\begin{array}{l}-1.956^{*} \\
(1.119)\end{array}$ \\
\hline Respondent's initial estimate $[25,50)$ & $\begin{array}{c}-0.809 \\
(1.2)\end{array}$ & & $\begin{array}{l}-0.83 \\
(1.201)\end{array}$ & \\
\hline Respondent's initial estimate $[50,75)$ & $\begin{array}{c}2.444 \\
(1.902)\end{array}$ & & $\begin{array}{c}2.55 \\
(1.893)\end{array}$ & \\
\hline Respondent's initial estimate $[75,100)$ & $\begin{array}{c}6.876 \\
(5.063)\end{array}$ & & $\begin{array}{c}6.576 \\
(5.045)\end{array}$ & \\
\hline Respondent's initial estimate $[0,10)$ & & $\begin{array}{l}-1.118 \\
(8.631)\end{array}$ & & $\begin{array}{l}-3.288 \\
(8.66)\end{array}$ \\
\hline Respondent's initial estimate $[10,20)$ & & $\begin{array}{c}0.653 \\
(8.538)\end{array}$ & & $\begin{array}{l}-1.409 \\
(8.558)\end{array}$ \\
\hline Respondent's initial estimate $[20,30)$ & & $\begin{array}{c}2.512 \\
(8.546)\end{array}$ & & $\begin{array}{l}0.545 \\
(8.58)\end{array}$ \\
\hline Respondent's initial estimate $[30,40)$ & & $\begin{array}{l}-0.458 \\
(8.556)\end{array}$ & & $\begin{array}{c}-2.663 \\
(8.6)\end{array}$ \\
\hline Respondent's initial estimate $[40,50)$ & & $\begin{array}{l}-1.798 \\
(8.607)\end{array}$ & & $\begin{array}{l}-3.741 \\
(8.658)\end{array}$ \\
\hline Respondent's initial estimate $[50,60)$ & & $\begin{array}{l}-3.092 \\
(8.926)\end{array}$ & & $\begin{array}{l}-5.096 \\
(8.982)\end{array}$ \\
\hline Respondent's initial estimate $[60,70)$ & & $\begin{array}{l}4.168 \\
(8.75)\end{array}$ & & $\begin{array}{l}2.313 \\
(8.792)\end{array}$ \\
\hline Respondent's initial estimate $[70,80)$ & & $\begin{array}{l}18.514^{*} \\
(9.615)\end{array}$ & & $\begin{array}{l}16.041^{*} \\
(9.634)\end{array}$ \\
\hline Respondent's initial estimate $[90,100]$ & & $\begin{array}{c}7.833 \\
(14.812)\end{array}$ & & $\begin{array}{c}2.258 \\
(14.754)\end{array}$ \\
\hline High political knowledge $(1=$ yes, $0=$ no $)$ & $\begin{array}{c}-3.336^{* *} \\
(1.491)\end{array}$ & $\begin{array}{l}-3.38^{* *} \\
(1.477)\end{array}$ & $\begin{array}{l}-3.27^{* *} \\
(1.491)\end{array}$ & $\begin{array}{c}-3.374^{* *} \\
(1.478)\end{array}$ \\
\hline Strong partisan by in-group bias ( $1=$ yes, $0=$ no) & & & $\begin{array}{l}-3.475^{*} \\
(1.857)\end{array}$ & $\begin{array}{c}-3.824^{* *} \\
(1.833)\end{array}$ \\
\hline Strong partisan by republican's feel $(1=y e s, 0=$ no $)$ & $\begin{array}{l}-3.044^{*} \\
(1.694)\end{array}$ & $\begin{array}{l}-3.52^{* *} \\
(1.678)\end{array}$ & & \\
\hline Observations & 484 & 484 & 484 & 484 \\
\hline $\mathrm{R} 2$ & 0.038 & 0.082 & 0.039 & 0.081 \\
\hline Adjusted R2 & 0.024 & 0.056 & 0.025 & 0.056 \\
\hline Residual Std. Error & $12.137(\mathrm{df}=476)$ & $11.936(\mathrm{df}=470)$ & $12.134(\mathrm{df}=476)$ & $11.937(\mathrm{df}=470)$ \\
\hline F Statistic & $2.704^{* * *}(\mathrm{df}=7 ; 476)$ & $3.211^{* * *}(\mathrm{df}=13 ; 470)$ & $2.745^{* * *}(\mathrm{df}=7 ; 476)$ & $3.207^{* * *}(\mathrm{df}=13 ; 470)$ \\
\hline
\end{tabular}


is conducted before or after the Iran Crisis. As Table 11 shows, we observe Republicans were significantly less likely to cooperate with Democrats after the assassination than before this event with 10 bins. The effect is weaker with 4 bins, however.

Table 11: Robustness Check for the Effect of Iran Crisis as in Figure 4

\begin{tabular}{|c|c|c|}
\hline & \multicolumn{2}{|c|}{ Dependent variable: first update } \\
\hline & Initial estimate with 4 bins & Initial estimate with 10 bins \\
\hline Intercept & $\begin{array}{c}15.444^{* * *} \\
(2.046)\end{array}$ & $\begin{array}{l}16.724^{*} \\
(8.793)\end{array}$ \\
\hline After Iran crisis $(1=$ yes, $0=$ no $)$ & $\begin{array}{l}-2.006^{*} \\
(1.125)\end{array}$ & $\begin{array}{c}-2.342^{* *} \\
(1.111)\end{array}$ \\
\hline Manipulation check $(1=$ yes, $0=$ no $)$ & $\begin{array}{c}-1.82 \\
(1.523)\end{array}$ & $\begin{array}{l}-1.771 \\
(1.51)\end{array}$ \\
\hline Male $(1=$ yes, $0=$ no $)$ & $\begin{array}{l}-2.13^{*} \\
(1.13)\end{array}$ & $\begin{array}{l}-2.085^{*} \\
(1.124)\end{array}$ \\
\hline Respondent's initial estimate $[25,50)$ & $\begin{array}{l}-0.479 \\
(1.187)\end{array}$ & \\
\hline Respondent's initial estimate $[50,75)$ & $\begin{array}{l}3.132^{*} \\
(1.883)\end{array}$ & \\
\hline Respondent's initial estimate $[75,100]$ & $\begin{array}{c}6.647 \\
(5.046)\end{array}$ & \\
\hline Respondent's initial estimate $[0,10)$ & & $\begin{array}{r}-3.033 \\
(8.64)\end{array}$ \\
\hline Respondent's initial estimate $[10,20)$ & & $\begin{array}{l}-1.268 \\
(8.543)\end{array}$ \\
\hline Respondent's initial estimate $[20,30)$ & & $\begin{array}{c}1.023 \\
(8.551)\end{array}$ \\
\hline Respondent's initial estimate $[30,40)$ & & $\begin{array}{l}-2.126 \\
(8.567)\end{array}$ \\
\hline Respondent's initial estimate $[40,50)$ & & $\begin{array}{l}-2.978 \\
(8.616)\end{array}$ \\
\hline Respondent's initial estimate $[50,60)$ & & $\begin{array}{l}-4.397 \\
(8.94)\end{array}$ \\
\hline Respondent's initial estimate $[60,70)$ & & $\begin{array}{l}3.254 \\
(8.75)\end{array}$ \\
\hline Respondent's initial estimate $[70,80)$ & & $\begin{array}{l}16.84^{*} \\
(9.601)\end{array}$ \\
\hline Respondent's initial estimate $[90,100]$ & & $\begin{array}{c}4.388 \\
(14.703)\end{array}$ \\
\hline High political knowledge $(1=$ yes, $0=$ no $)$ & $\begin{array}{c}-2.974^{* *} \\
(1.5)\end{array}$ & $\begin{array}{c}-3.026^{* *} \\
(1.485)\end{array}$ \\
\hline Observations & 485.0 & 485.0 \\
\hline $\mathrm{R} 2$ & 0.038 & 0.082 \\
\hline Adjusted R2 & 0.024 & 0.056 \\
\hline Residual Std. Error & $12.126(\mathrm{df}=477)$ & $11.923(\mathrm{df}=471)$ \\
\hline F Statistic & $2.696^{* * *}(\mathrm{df}=7 ; 477)$ & $3.22^{* * *}(\mathrm{df}=13 ; 471)$ \\
\hline
\end{tabular}




\subsection{Updating Behavior Beyond the First Round}

Thus far we have only discussed the updating behavior of respondents after they viewed the estimate of the bot impersonating a member of the opposing party for the first time. This is because the most consequential effect of exposure to a member of the opposing party is likely to occur during the initial exposure. Yet our study allowed respondents to update their estimates during three subsequent rounds of updating in response to the bot's estimates. Even though exposure to party affiliation during these rounds is redundant, we analyzed updating behavior among Republicans and Democrats across each of these rounds but observed negligible or small treatment effects in so doing. Between the second and third round of updating, we observed no significant differences in the updating behavior of Republican respondents $(\mathrm{p}>0.05, \mathrm{~N}=$ 464) and a small negative updating effect among Democrats who were exposed to the common enemy prime ( $\mathrm{p}<0.05, \mathrm{~N}=504)$ but not the patriotic prime $(\mathrm{p}>0.05, \mathrm{~N}=504)$. Between the third and fourth round of updating, we observed no statistically significant differences in updating behavior among either Republicans ( $\mathrm{p}>0.05, \mathrm{~N}=441)$ or Democrats $(\mathrm{p}>0.05, \mathrm{~N}$ $=487$ ). Similarly, between the fourth and fifth rounds, we observed no statistically significant differences in updating behavior among either Republicans ( $\mathrm{p}>0.05, \mathrm{~N}=450$ ) or Democrats ( $p>0.05, N=504)$. Finally, the bot type did not have a significant effect on the final update, from first to last estimate, of either Republicans or Democrats.

\subsection{Deviations from Preregistration}

The full text of our pre-registration is available via the Open Science Framework at this link. Though we focused upon our pre-registered hypotheses about asymmetric polarization in the main text of our article, some of our predictions about this process were not supported by our analysis. For example, we initially hypothesized we would observe asymmetric polarization across both of our treatment conditions (patriotic and common enemy priming), but we only 
found evidence of this process in the latter condition. We also pre-registered rival hypotheses that were not supported by our findings. Based on the common ingroup identity model, we expected participants in our common enemy and patriotic priming conditions to incorporate more information from the outgroup bot; this hypothesis was not supported $(\mathrm{p}>0.05, \mathrm{~N}=$ 1015).

We made a separate set of predictions about how people would behave in response to different types of behavior by our bot. More specifically, we expected participants to cooperate more with the friendly bot (that updates its estimates towards respondents) than the stubborn bot (which does not). We did not find consistent evidence of this behavior. Since it takes more than one round for the player to discern the bot's behavior (as either friendly or stubborn), we compare the difference in updates between the first and final estimating rounds via models that include the same controls as those reported in Figure 2 from the main text; updating is not significantly affected by the bot type ( $\mathrm{p}>0.05, \mathrm{~N}=992)$. We also predicted that participants in the priming conditions would be more likely to incorporate information from the stubborn bot than participants in the control condition. However based on our data, updating towards the stubborn bot does not significantly differ by condition ( $\mathrm{p}>0.05$ for both the enemy and patriotic prime, $\mathrm{N}$ = 502). However, we observe that the Republicans update significantly more towards the stubborn bot $(\mathrm{p}<0.01, \mathrm{~N}=521)$, while Democrats exhibit no significant differences $(\mathrm{p}>0.05$, $\mathrm{N}=471$ ). We preregistered competing hypotheses about whether Democrats or Republicans would be more accommodating of the stubborn bot, but found that the two do not differ in their willingness to update towards the stubborn bot (total update from the first to the final round; $p$ $>0.05, \mathrm{~N}=983)$.

Our analyses of the data also deviated from our pre-registration statement in several significant ways. In that document, we proposed to evaluate our hypotheses by examining updating behavior within each estimation round and between the first and last round. Yet we did not 
realize that a) information about the party affiliation of the bot impersonating a member of the opposing party would be redundant after the first round of updating; and, b) people's experience of the bot's initial guess would be more consequential than subsequent rounds because of the considerable heterogeneity in respondents' initial estimates. For these reasons, we elected to focus on the updating behavior of respondents between the first two rounds and reported the other models in our Supplementary Materials (above). In our pre-registration document, we also stated that we would control for the type of bot (friendly or stubborn) in our analyses. Because we did not observe significant interactions between bot behavior and our priming conditionsand because we adopted the aforementioned binned measure of respondent's initial estimate, which interacts with bot behavior - we elected not to include this measure in our models. We also pre-registered a mediation analysis. More specifically, we included measures of personal affect (PANAS), and ingroup and outgroup identification (identification question) as potential mediators of any effect to the patriotic and common enemy primes. When conducting mediation analyses, these mediators did not predict cooperation with the outgroup bot. In retrospect, we concluded that these measures may not have been effective because they were administered after the prime and the estimation task had been completed, rather than immediately after the prime. Finally, we did not pre-register our analyses of the pre and post-Iran crisis effects of the common enemy prime because it was not possible to anticipate such unprecedented events at the time we wrote our pre-registration statement.

\section{References and Notes}

1. D. Baldassarri, P. Bearman, American Sociological Review 72, 784 (2007).

2. L. Boxell, M. Gentzkow, J. M. Shapiro, Proceedings of the National Academy of Sciences 114, 10612 (2017). 
3. S. Iyengar, Y. Lelkes, M. Levendusky, N. Malhotra, S. J. Westwood, Annual Review of Political Science 22, 129 (2019).

4. M. P. Fiorina, S. J. Abrams, Annual Review of Political Science. 11, 563 (2008).

5. M. Macy, S. Deri, A. Ruch, N. Tong, Science Advances 5, eaax0754 (2019).

6. ANES, 2016 Time Series Study.

7. S. Iyengar, G. Sood, Y. Lelkes, The Public Opinion Quarterly 76, 405 (2012).

8. F. Heider, The Journal of Psychology 21, 107 (1946).

9. G. Simmel, Conflict / The Web Of Group Affiliations (Free Press, 1955), first edn.

10. L. Coser, The Functions of Social Conflict-Free Press (The Free Press, 1956).

11. M. B. Brewer, Social Identity Processes: Trends in Theory and Research (SAGE Publications Ltd, London, 2000), pp. 118-132.

12. R. Brubaker, Annual Review of Sociology 35, 21 (2009).

13. S. L. Gaertner, J. F. Dovidio, P. A. Anastasio, B. A. Bachman, M. C. Rust, European Review of Social Psychology 4, 1 (1993). Publisher: Routledge.

14. M. C. Desch, International Organization 50, 237 (1996).

15. S. Walt, Foreign Policy (2016).

16. J. Skrentny, Theory and Society 27, 237 (1998).

17. D. L. Sullivan, M. J. Landau, Z. K. Rothschild, Journal of Personality and Social Psychology 98, 434 (2010). 
18. D. M. Gibler, The Journal of Conflict Resolution 54, 519 (2010). Publisher: Sage Publications, Inc.

19. J.-K. Choi, S. Bowles, Science 318, 636 (2007).

20. M. A. Hogg, Advances in Experimental Social Psychology 39, 69 (2007).

21. C. Budak, S. Goel, J. M. Rao, Public Opinion Quarterly 80, 250 (2016). Publisher: Oxford Academic.

22. M. Prior, G. Sood, K. Khanna, Quarterly Journal of Political Science 10, 489 (2015).

23. M. Grossmann, D. A. Hopkins, Asymmetric Politics: Ideological Republicans and Group Interest Democrats (Oxford University Press, New York, NY, 2016), first edn.

24. C. A. Bail, et al., Proceedings of the National Academy of Sciences 115, 9216 (2018).

25. D. Guilbeault, J. Becker, D. Centola, Proceedings of the National Academy of Sciences 115, 9714 (2018).

26. D. J. Ahler, G. Sood, The Journal of Politics 80, 964 (2018).

27. D. Lazer, et al., Science 323, 721 (2009).

28. D. C. Molden, Understanding priming effects in social psychology (Guilford Press, New York, NY, US, 2014), pp. 252-258.

29. J. Muñoz, A. Falcó-Gimeno, E. Hernández, Political Analysis 28, 186 (2020). Publisher: Cambridge University Press.

30. A. Berinsky, G. Huber, L. Gabriel, Political Analysis 20, 351 (2012).

31. L. Litman, J. Robinson, T. Abberbock, Behavior Research Methods 49, 433 (2017). 
32. A. Almaatouq, et al., arXiv preprint arXiv:2006.11398 (2020).

33. D. Watson, L. A. Clark, A. Tellegen, Journal of Personality and Social Psychology 54, 1063 (1988).

34. M. S. Levendusky, The Journal of Politics 80, 59 (2018).

35. J. M. Box-Steffensmeier, S. De Boef, T.-M. Lin, American Political Science Review 98, 515 (2004).

36. D. Holt, T. F. Smith, Journal of the Royal Statistical Society: Series A (General) 142, 33 (1979).

37. T. Lumley, Journal of Statistical Software, Articles 9, 1 (2004). 